\title{
A detailed microstructural and corrosion analysis of an additively manufactured magnesium alloy produced by selective laser melting
}

\author{
Mohsen Esmaily ${ }^{1,2}$, Zhuoran Zeng ${ }^{2}$, Nooshin Mortazavi ${ }^{2,3}$, Alessio Gullino ${ }^{2,4}$, Sanjay \\ Choudhary $^{2}$, Thomas Derra ${ }^{5}$, Felix Benn ${ }^{5,6}$, Francesco D'Elia ${ }^{5}$, Max Müther ${ }^{5}$, Sebastian \\ Thomas $^{2}$, Aijun Huang ${ }^{2,7}$, Antoine Allanore ${ }^{1}$, Alexander Kopp ${ }^{5}$, Nick Birbilis ${ }^{8}$ \\ ${ }^{1}$ Department of Materials Science and Engineering, Massachusetts Institute of Technology, \\ Cambridge, MA, United States \\ ${ }^{2}$ Department of Materials Science and Engineering, Monash University, Clayton, VIC, \\ Australia \\ ${ }^{3}$ John A. Paulson School of Engineering and Applied Sciences, Harvard University, \\ Cambridge, MA, United States \\ ${ }^{4}$ Department of Electronics and Telecommunications, Politecnico di Torino, Torino, Italy \\ ${ }^{5}$ Meotec GmbH, Philipsstr. 8, Aachen, Germany \\ ${ }^{6}$ School of Mechanical and Aerospace Engineering, Queens University Belfast, Belfast, UK \\ ${ }^{7}$ Monash Centre for Additive Manufacturing, Notting Hill, VIC, Australia \\ ${ }^{8}$ College of Engineering and Computer Science, The Australian National University, \\ Canberra, ACT, Australia
}

\begin{abstract}
Magnesium (Mg) alloys have promising potentials for lightweight and biomedical applications. Although there has been a recent interest in producing Mg alloys (including AZ, ZK and WE series) using additive manufacturing (AM), the process-structure-corrosion properties relationships in $\mathrm{AM} \mathrm{Mg}$ alloys are yet to be understood. Herein, the production of $\mathrm{Mg}$ alloy WE43 was achieved by selective laser melting (SLM). The alloy was investigated after SLM, hot isostatic pressing (HIP) as well as an additional solutionising heat treatment. Specimens were carefully characterised, whilst assessed and contrast relative to the conventionally cast alloy counterpart. Characterisation included detailed microstructural analysis employing analytical transmission electron microscopy, X-ray mapping, and electron backscatter diffraction, which revealed the SLM prepared specimens possess a unique microstructure comprising fine grains growing with a strong [0001] texture along the building direction. The SLM prepared specimens also revealed a low fraction of process-induced and metallurgical defects, reaching $<0.1 \%$ after optimising the SLM parameters and HIP treatment. The SLM prepared WE43 was found to be cathodically more active relative to the cast WE43 because of a fine distribution of zirconium-, yttrium- and oxygen-rich particles as well as the alterations in the chemical composition of the solid-solution matrix originating from the high cooling rates of SLM. It was revealed that the oxide particles were mainly sourced by powder and thus it is hypothesised that the corrosion of SLM prepared Mg alloys could be greatly improved once the influence of powder characteristics is further understood and controlled.
\end{abstract}

Keywords: Magnesium alloy; WE43; heat treatment; selective laser melting; corrosion; microstructure 


\section{Introduction}

Additive manufacturing (AM) of metallic materials continues to present significant potential for unique manufacturing in the context of novel design, innovation and resource use. The metal AM sector may witness, as estimated, revenues over $\$ 11$ billion in 2024; with the AM of metallic materials including stainless steels [1,2], nickel (Ni) alloys [3], titanium (Ti) alloys [4] and aluminium (Al) alloys [5, 6] presently an integral fabrication process for both critical and non-critical metallic components - across diverse technological areas.

In the pursuit of extending the portfolio of metals and alloys pursued in the context of AM, there is also a growing interest in exploring the potential of $\mathrm{AM}$ to produce magnesium $(\mathrm{Mg})$ alloy components. Magnesium and its alloys are the lightest engineering materials (1.4 - 2.0 $\mathrm{g} / \mathrm{cm}^{3}$ ), and possess properties such as recyclability, weld-ability, and high specific strength. The combination of lightweight and high specific strength, lends possibilities in the context of complex net-shape components for numerous applications, from biomedical, to defence, to 3C (Computers, Communications and Consumer Electronics) applications [7]. In the context of metallic biomaterials for orthopaedic applications, AM has already demonstrated excellent applicability in custom permanent implants (e.g., Ti-alloys) and such customisation would be translatable to $\mathrm{Mg}$ components. Magnesium alloys - unlike permanent implant materials display unique biocompatibility and an ability to degrade in vivo, with numerous experiments having revealed $\mathrm{Mg}$ ions $\left(\mathrm{Mg}^{2+}\right)$ can promote human metabolism, mediate osteoblast proliferation and enhance osteoblastic differentiation [8].

Although there exists a plethora of studies on the processing, microstructure and physical properties of Mg-based alloys (see e.g., [9-17]), to date, there remains a limited reporting, characterisation and rationalisation of processing-structure-properties relationships for AM produced Mg alloys [18-20]. In part this is because the production of Mg-based alloys by AM has been considered complicated, owing to a range of factors that could include: safety concerns associated with the reactive nature of $\mathrm{Mg}$ powder; the superheating and boiling / evaporation of $\mathrm{Mg}$ via interaction with laser based methods; a tendency for ignition in the presence of common environments ( $\mathrm{Mg}$ can burn under air or $\mathrm{N}_{2}$ ), and even supply chain issues for $\mathrm{Mg}$ powder of suitable size and composition (relevant to powder based AM). However, with the maturation of commercial AM and the ability to leverage decades of $\mathrm{Mg}$ research and development, contemporary safety awareness and the established protective measures permit the AM of Mg alloys. A synopsis of research regarding the AM of Mg-alloys has been compiled as a timeline and is represented in Fig. 1. 
To date, utilisation of $\mathrm{AM}$ for producing $\mathrm{Mg}$ and its alloys have been confined to a small number of alloy systems, including the $\mathrm{AZ}[21,22]$ and $\mathrm{ZK}[23,24]$ series of Mg-alloys, as well Mg-alloys containing rare earth (RE) elements [18-20, 25, 26]. The earliest reports utilising AM for producing Mg parts were carried out by $\mathrm{Ng}$ et al. [27, 28] in 2010 and 2011 - where the authors developed and utilised a laser sintering technique, employing a pulsed Nd:YAG laser. Their configuration operated with a relatively large spot size as compared to the current commercial SLM instruments (i.e., $600 \mu \mathrm{m}$ vs. $<100 \mu \mathrm{m}$ ), and a shielding box of argon (Ar) gas to minimise the environmental reaction and oxidation. $\mathrm{Ng}$ et al. [27, 28] reported single-track formation from laser sintering of the pure $\mathrm{Mg}$ powder, noting an increase in the oxygen content of the sintered regions as compared with the feedstock $\mathrm{Mg}$ powder. Their observation regarding oxygen pick-up of sintered zones is concomitant with the extremely high affinity of $\mathrm{Mg}$ for any residual or impurity oxygen.

Zhang et al. [21] were the first to sinter an Mg alloy using the now-well known selective laser melting (SLM) approach. In that work, the authors sintered an $\mathrm{Mg}-9 \% \mathrm{Al}$ powder mixture, and studied the effects of laser power input and lower scanning speed on densification of microstructure of the as-built specimens. The authors also reported the oxidation issue arising from the interactions between $\mathrm{Mg}$ and the atmosphere of the process chamber. In order to understand the persistent oxidation issue, Salehi et al. [29] utilised thermogravimetric analysis (TGA) in conjunction with thermodynamic calculations to study the reaction of $\mathrm{Mg}$ powder during AM in a process chamber filled with argon gas and (oxygen) impurities. They reported that even ultra-high purity (99.9999\%) Ar gas containing $<10 \mathrm{ppb}_{2},<20 \mathrm{ppb}_{2} \mathrm{O}$ and $<$ $10 \mathrm{ppm} \mathrm{N}_{2}$ used for TGA could only provide inert atmosphere for $\mathrm{Mg}$ powder up to $400^{\circ} \mathrm{C}$. For temperatures exceeding $400{ }^{\circ} \mathrm{C}, \mathrm{Mg}$ powder significantly reacted with oxygen content present as an impurity in $\mathrm{Ar}$ gas to form $\mathrm{MgO}$ (and $\left.\mathrm{Mg}(\mathrm{OH})_{2}\right)$ [29].

The timeline (Fig. 1) reveals that the majority of activity in the field of AM of Mg-alloys has been maturing since $\sim 2010$, including the production of bulk (3D) samples with complex geometries with specific applications in the biomedical sectors. The recent research has principally focused on the AM of Mg alloy WE43, which is an $\mathrm{Mg}$ - yttrium (Y) - rare earth (RE) alloy system $[18-20,25,26]$. The integers in the WE43 designation refer to a nominal alloy composition of $\sim 4$ wt. \% Y and 3 wt. \% RE (which may be a combination of neodymium $(\mathrm{Nd})$, lanthanum $(\mathrm{La})$ and cerium $(\mathrm{Ce})$ ), with such alloys nominally containing $<0.5$ wt. \% zirconium $(\mathrm{Zr})$, which is a functional alloying element utilised for grain refining. Magnesium 
alloys containing RE elements, including WE43 and WE54 offer improved ambient and hightemperature mechanical (tensile and creep) properties via thermally stable microstructures, along with adequate corrosion resistance, and ignition resistance during casting [30-32].

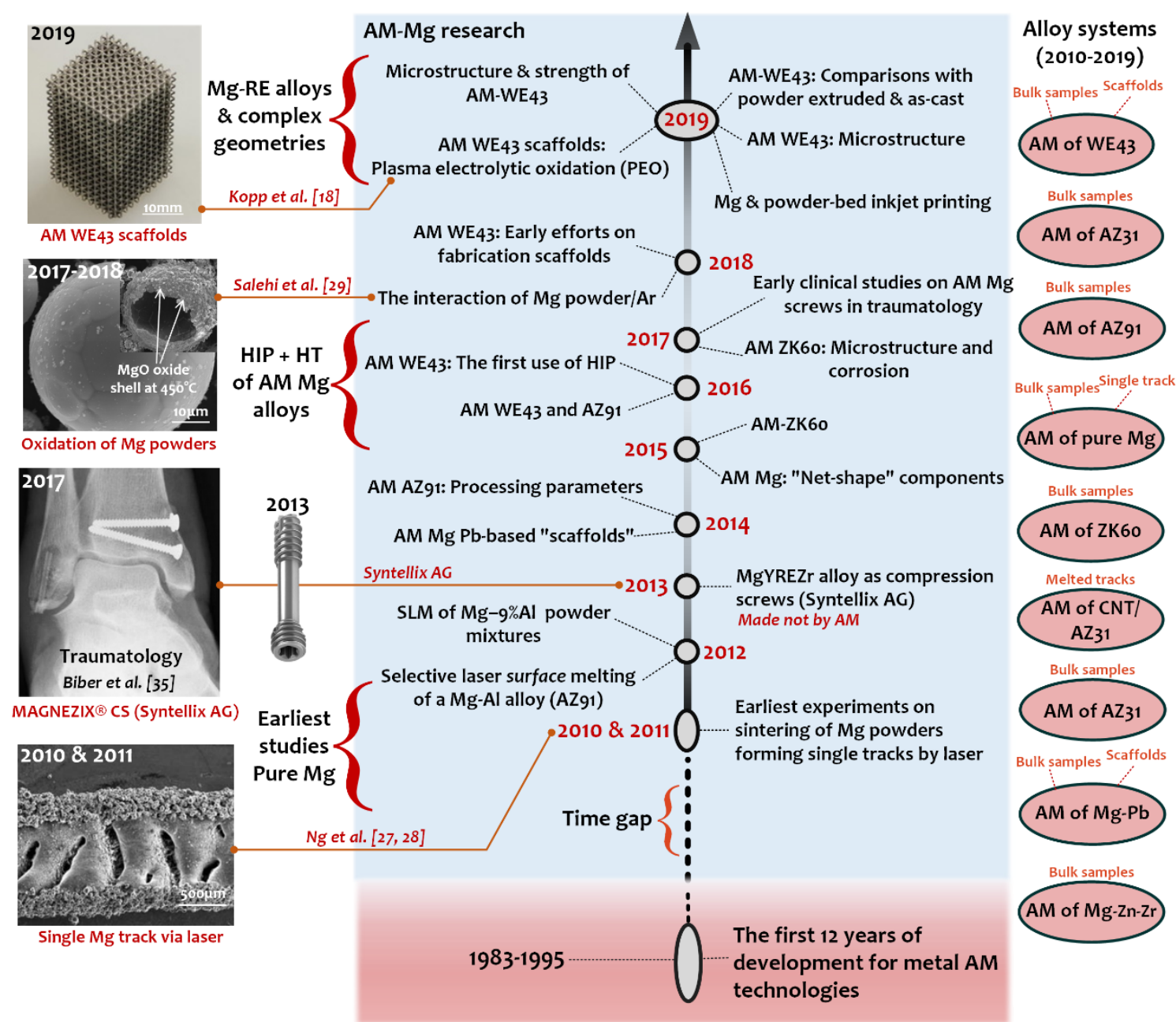

Figure 1. Timeline displaying a historical background of AM-Mg research and development, indicating "landmarks" since the first scientific study on utilisation of AM to sinter Mg powder, from [18-29, 33-38]. The images shown in the left-hand side were reproduced with permission from Elsevier. Note the difference in the geometrical complexity that can be accomplished by AM (i.e., the scaffold) as compared to other state-of-the-art manufacturing technologies (i.e., the compression screw).

Most recently, studies regarding the microstructure and physical properties of SLM manufactured WE43 in the bulk as well as complex geometries have emerged. The first generation of SLM prepared WE43 scaffolds (often also termed topologically ordered porous structures) was produced and reported by Li et al. [25]. In their study, they reported the in vitro biodegradation behaviour, mechanical properties and biocompatibility of the green specimens, surmising that SLM prepared samples exhibit the potential to satisfy the functional 
requirements of an ideal bone substituting material. Subsequently, Zumdick et al. [20] used SLM to manufacture bulk cubic specimens from WE43, investigated the microstructure and mechanical properties of the as-SLM material and compared their results with those of powder extruded and as-cast materials. In that study, they observed a higher yield strength and significantly higher ultimate tensile strength in the SLM prepared samples as compared with those of their cast counterparts. Most recently, Gangireddy et al. [19] examined the effect of SLM parameters and hot isostatic pressing (HIP) on the microstructure and mechanical properties of WE43. The authors noted that HIP is an effective approach for ensuring complete densification of the SLM prepared sample, whilst also noting that green (i.e. as-SLM) samples revealed enhanced strength relative the conventional cast WE43 alloy counterpart.

The efforts in the studies cited above are pioneering in the context of SLM prepared Mg-alloys, and have identified a need for continued research to illuminate the understanding of the process-structure-corrosion property relationships in SLM prepared Mg-alloys. In particular, the corrosion behaviour of SLM prepared Mg-alloys remains limited to date, however studying the corrosion of $\mathrm{Mg}$ alloys remains critical prior to service - given that corrosion is known to limit the utility of $\mathrm{Mg}$ alloys in numerous applications. To permit the full potential of the advantages associated with AM (including design freedom and attendant mechanical properties), it is required to address these imperative knowledge gaps. Therefore, the study herein investigates the microstructure, electrochemical behaviour and corrosion response of WE43 prepared in three conditions, namely as-SLM, SLM+HIP, and SLM + HIP + heat treatment, whilst and comparing these conditions with those of conventionally cast WE43 as a reference material. Furthermore, the role of processing parameters in the corrosion response of the alloy was also carefully investigated. 


\section{Material and methods}

Powder material Additively manufactured WE43 specimens were produced from WE43 powder (which is shown in the micrographs in Fig. 2a) using selective laser melting (SLM). The WE43 powder (WE43MEO, Meotec $\mathrm{GmbH}$ ) was prepared within the compositional specifications shown in Table 1, and prepared chill casting and subsequently powderised by gas atomisation. The powder particle size distribution was determined to have a D10 of $30 \pm$ $8 \mu \mathrm{m}, \mathrm{D} 50$ of $45 \pm 8 \mu \mathrm{m}$ and a D90 of $65 \pm 8 \mu \mathrm{m}$.

Table 1. Chemical composition of the WE43 powder used for SLM.

\begin{tabular}{ll}
\hline Element & $\mathrm{Wt} . \%$ \\
\hline $\mathrm{Mg}$ & Balance \\
$\mathrm{Y}$ & $3.6-4.4$ \\
$\mathrm{Nd}$ & $2.2-3.5$ \\
$\mathrm{Zr}$ & $0.4-0.6$ \\
$\mathrm{Mn}$ & $0-0.04$ \\
$\mathrm{Si}$ & $0-0.01$ \\
$\mathrm{Cu}$ & $0-0.01$ \\
$\mathrm{Fe}$ & $0-0.005$ \\
$\mathrm{Zn}$ & $0-0.004$ \\
$\mathrm{Al}$ & $0-0.035$ \\
$\mathrm{Ni}$ & $0-0.003$ \\
$\mathrm{Be}$ & $0-0.002$ \\
$\mathrm{Others}$ & $<0.1$ \\
\hline
\end{tabular}

Selective laser melting The SLM method (Fig. 2b), which is a laser powder bed fusion (LPBF)based AM technique, was employed herein for the preparation of specimens. The customised SLM build chamber, comprising an atmosphere of pure inert argon (5.0), was based on an AconityMINI system (Aconity3D GmbH, Germany). The densification, microstructure and physical properties of the SLM prepared samples is governed by the composition/quality of the feedstock material (powder) and the SLM processing parameters including laser power $(P ; \mathrm{W})$, scanning speed $(V ; \mathrm{mm} / \mathrm{s})$, hatching distance $(h ; \mu \mathrm{m})$, layer thickness $(d ; \mu \mathrm{m})$ and scan strategy (laser path / pattern). While previous studies $([18,20])$ have prepared similar alloys by the SLM technique, the two most crucial processing parameters, namely laser power and scan speed, were nonetheless carefully optimised in this work to report a holistic study. A scan strategy employing parallel lines and orthogonal orientation respective to the previous layer was selected in order to minimise internal stresses and macroscopic porosity, in an attempt to not detriment mechanical performance. A zig-zag laser exposure pattern with the scanning angle (between adjacent layers) of $90^{\circ}$ was used (Fig. 2c). The build chamber was continuously flooded with argon at a rate of $5 \mathrm{l} / \mathrm{min}$, whilst the chamber was also equipped with an additional gas circulation system to minimise oxidation and to reduce metal vapor in the chamber. 
The specimens were fabricated using a hatch spacing of $40 \mu \mathrm{m}$, a layer thickness of $30 \mu \mathrm{m}$, and a focus diameter of $90 \mu \mathrm{m}$. In order to optimise power and scan speed, a matrix of specimen preparation conditions was explored using laser powers in the range of $40-400 \mathrm{~W}$ and scan speeds in the range of $200-2000 \mathrm{~mm} / \mathrm{s}$. The process parameters were optimised in terms of the specimen quality (which was user-defined to include density, dimensional accuracy, mechanical properties and evaporation of $\mathrm{Mg}$ powder). Cylindrical test specimens for the microstructural and corrosion investigations were prepared with a diameter of $6 \mathrm{~mm}$ and height of $30 \mathrm{~mm}$. A synopsis of the powder, SLM set-up and scan strategy are summarised in Fig. 2.
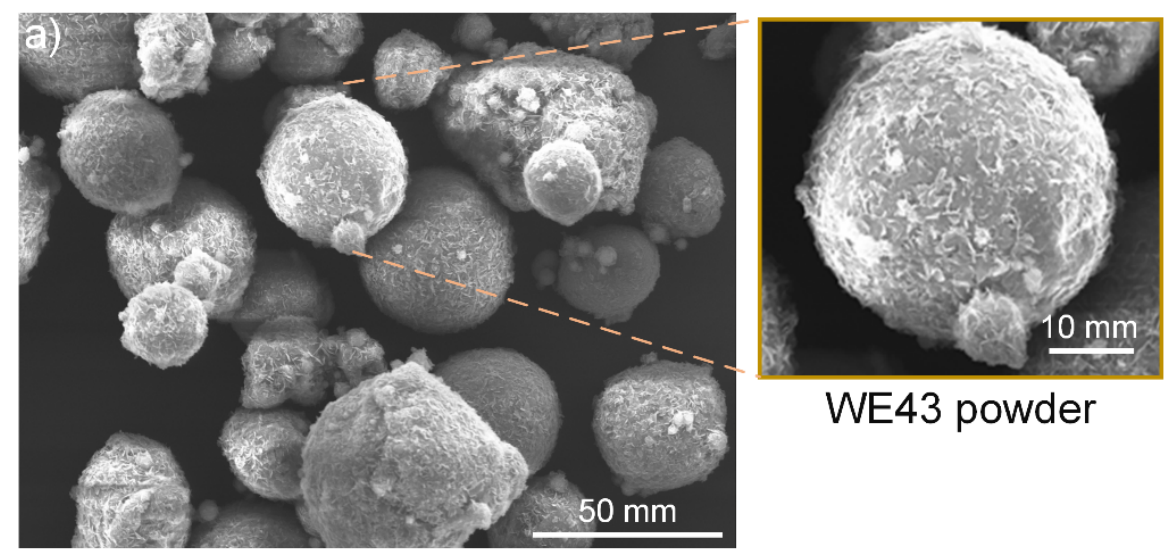

WE43 powder
Composition in wt. \%:

Mg: Balance

$Y: 3.6-4.4$

Nd: $2.2-3.5$

Zr: $0.4-0.6$

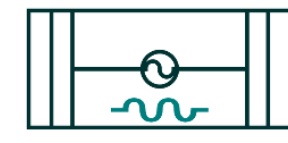

Laser system/

Energy source

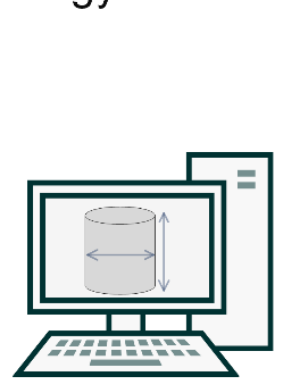

3D-CAD model

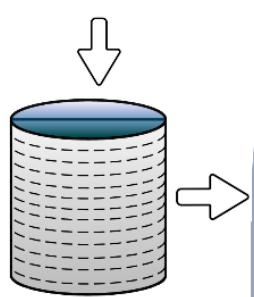

Slicing

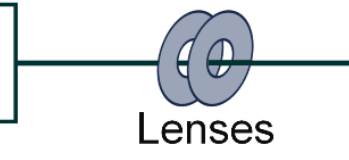

Lenses

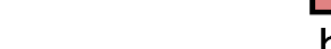

$X-Y$ Scanning mirrors

b)
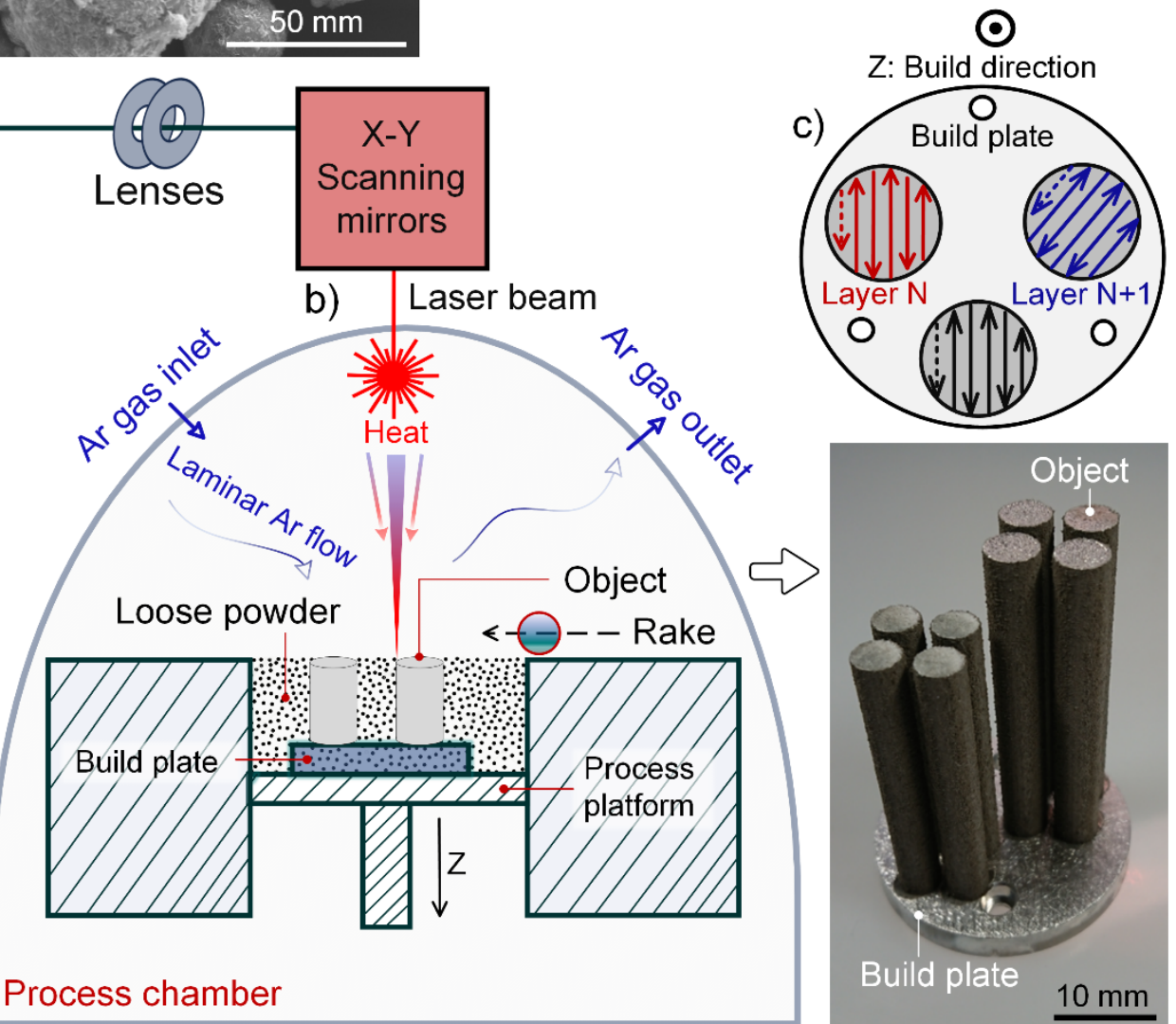

Figure 2. (a) The characteristic morphology of the WE43 powder and its nominal chemical composition used for SLM, $(b)$ a schematic of the SLM process used in this study and the cylindrical samples manufactured by SLM, and $(c)$ the scanning strategy used in this study. 
In the present study, some of the as-SLM (green or as-built) specimens were subject to HIP at $520^{\circ} \mathrm{C}$ and $103 \mathrm{MPa}$ for $4 \mathrm{~h}$ under Argon gas. Subjecting the as-SLM specimens to both high temperature and isostatic gas pressure was executed to fully densify samples and to improve mechanical properties by precipitation hardening. Following the HIPing procedure, some specimens were also subsequently solutionised under Argon protection at $525^{\circ} \mathrm{C}$ for $8 \mathrm{~h}$. Prior to the microstructural and corrosion experiments, test specimens (which will herein be denoted as: as-SLMed, SLM+ HIP, and SLM + HIP + HT) were cut from the cylindrical samples and metallographically prepared. This involved metallographic grinding (lubricated with deionised water) through successive grades of abrasive silicon carbide papers from P1000 to P4000 mesh. Polishing was performed using diamond paste of $1 \mu \mathrm{m}$ on cloth, followed by a fine polishing step of oxidized porous silicon on a Buehler Microcloth ${ }^{\circledR}$ for 20 minutes, as described in [39].

Microstructural Characterisation Phase analysis of the SLM prepared and cast materials was conducted using X-ray diffraction (XRD) by means of a Bruker D8 Advance X-ray diffractometer with $\mathrm{Cu}-\mathrm{K} \alpha$ radiation $(\lambda=0.154 \mathrm{~nm})$ operating at $40 \mathrm{kV}$ and $40 \mathrm{~mA}$. The XRD data were assessed using ICDD PDF 4 and Bruker Eva ${ }^{\circledR}$ software. The microstructural features and morphology of the corrosion products were studied using an FEI Quanta 3D-FEG scanning electron microscope in the backscattered electron (BSE) and secondary electron (SE) modes. The instrument was equipped with energy dispersive X-ray spectroscopy (EDXS) from Oxford instruments AZtec ${ }^{\circledR}$ X-ray analysis system. Image analysis (e.g. calculating the fraction of various phases and pores in samples of various conditions) was carried out using Adobe Photoshop CS4 ${ }^{\circledR}$, Image Pro-Plus ${ }^{\circledR}$ and Image ${ }^{\circledR}$.

In order to study the grain structure, electron back-scatter diffraction (EBSD) was performed (FEI Quanta 3D-FEG) with a Pegasus Hikari EBSD detector and TSL ${ }^{\circledR}$ OIM control system. The TSL ${ }^{\circledR}$ OIM 7 software was employed to process data. Herein, the step size used was 500 $\mathrm{nm}$ and a high-angle grain boundary (HAGB) was defined as a boundary with a misorientation of $>15^{\circ}$, whilst a low-angle grain boundary (LAGB) was defined as a misorientation between $2^{\circ}$ and $15^{\circ}$. A grain was defined as the cellular structure enclosed by a HAGB, and sub-grain defined as the cellular structure enclosed by a LAGB [40]. The size of a grain was determined by the equivalent diameter calculated from the measured grain area by $2 \sqrt{\frac{\sqrt{\text { rain area }}}{\pi}}$.

The specimen nanostructure was also investigated by means of scanning transmission electron microscopy (STEM) using a FEI Tecnai F20 TEM operating at an accelerating voltage $200 \mathrm{kV}$ and equipped with a Bruker XFlash 6TI30 X-ray detector. Imaging was carried out in bright 
field (BF) and high-angle annular dark-field (HAADF) modes. The STEM-EDXS point analysis and mapping data was processed using Bruker Spirit 1.9 software. Specimens analysed were $3 \mathrm{~mm}$ discs prepared by mechanical grinding to $0.05 \mathrm{~mm}$ and subsequently ion polished using a Gatan PIPS II operating at $4.8 \mathrm{kV}$ and $-100^{\circ} \mathrm{C}$ with a tilt of $4^{\circ}$, followed by further milling at $0.5 \mathrm{kV}$ and $-100^{\circ} \mathrm{C}$ with a tilt of $2^{\circ}$.

Electrochemical measurements A conventional three-electrode flat cell electrochemical configuration was utilised (K-0235 cell, Princeton Applied Research) with a $1 \mathrm{~cm}^{2}$ working electrode area exposed to quiescent $0.1 \mathrm{M} \mathrm{NaCl}$. A saturated calomel electrode (SCE) reference electrode and Pt-mesh counter electrode were employed, with electrochemical testing carried out using a Bio-Logic ${ }^{\circledR}$ VMP 3 potentiostat. Potentiodynamic polarisation testing was conducted using a scan rate of $1 \mathrm{mV} / \mathrm{s}$, and prior to polarisation, specimens were conditioned at open circuit potential (OCP) for $10 \mathrm{~min}$. The corrosion potential $\left(E_{\text {corr }}\right)$ and corrosion current densities $\left(i_{\text {corr }}\right)$ was determined from via a Tafel-type fit using EC-Lab software. In separate testing, following various OCP exposure periods, electrochemical impedance spectroscopy (EIS) was conducted on independent samples over the frequency range of $100 \mathrm{kHz}-10 \mathrm{mHz}$. The EIS spectra were fitted using EC-Lab software. In all cases, four replicate tests for each electrochemical test were performed to ensure reproducibility.

Hydrogen collection, mass loss and immersion testing Mass loss tests were performed in 0.1 $\mathrm{M} \mathrm{NaCl}$ at ambient laboratory temperature (maintained at $23{ }^{\circ} \mathrm{C}$ ). An analytical balance with an accuracy of $0.01 \mathrm{mg}$ was utilised to weigh the specimens before the mass loss experiments. Mass loss experiments were conducted in conjunction with volumetric hydrogen collection using an inverted funnel inserted into a burette. Following this exposure testing, specimens were cleaned of corrosion products using a chromate solution of $20 \% \mathrm{CrO}_{3}$ for $15 \mathrm{~s}$, followed by several periods of $30 \mathrm{~s}[39,41]$. Additionally, a number of unique exposure times were employed in order to study corrosion morphology using optical microscopy and SEM. In such cases, specimens were immersed in $0.1 \mathrm{M} \mathrm{NaCl}\left(23^{\circ} \mathrm{C}\right)$ for durations denoted in the associated results section where both optical and electron micrographs are presented. Corrosion morphology, corroded surfaces and cross-sections were observed using SEM following removal of corrosion products using the standard cleaning process (ASTM-G1-03). 


\section{Results}

\subsection{SLM Process map for WE43}

In order to explore the combined effect of laser power $(P)$ and scan speed $(v)$ involved in the individual line scanning, the initial aspects of this study sought to establish a process map in order to identify appropriate parameters for producing specimens with minimal defects (Fig. 3). While optimising process parameters was not the objective of this study, such a step is a critical precursor to reporting meaningful properties that correspond to a desired quality of the specimens manufactured by SLM. The construction of the process map was performed by producing numerous (WE43) specimens using a range of laser power and scan speed. In the LPBF-based methods, the formation of defects depends on the wetting of molten pool, which is governed by the two critical process parameters: $(i)$ laser power and (ii) scan speed. As such, increasing laser power provides more energy for powder consolidation whilst improving molten pool wetting and decreasing scan speed increases the laser-matter interaction time, making the movement of the liquid metal less violent [42, 43].

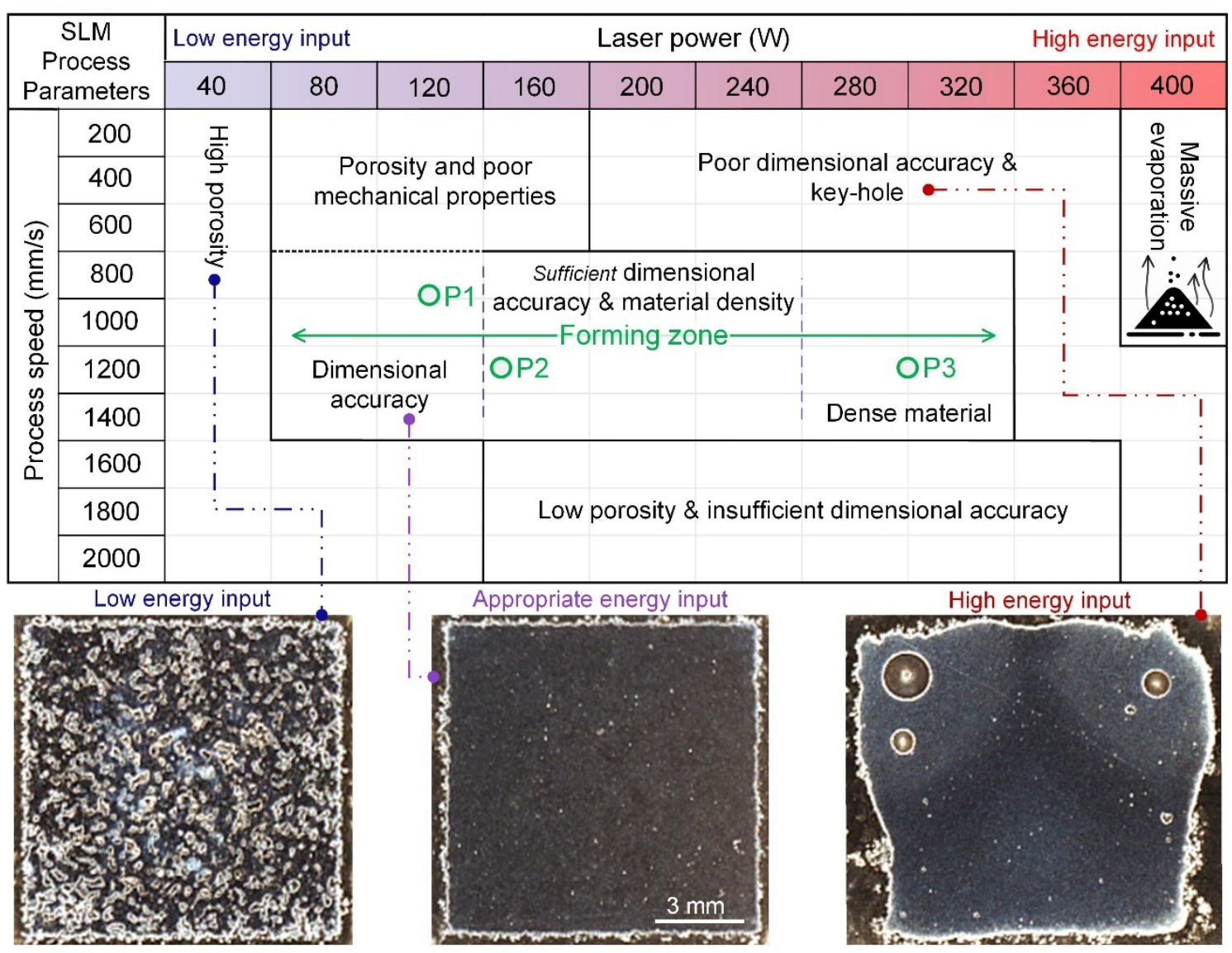

Figure 3. Power-speed process map for SLM prepared WE43. The map also shows the selected process parameters (P 1-3 corresponding to Parameters 1-3) used to manufacture the SLM prepared specimens. 
Thus, a trade-off between the scan speed and laser power is required to achieve the appropriate range of molten pool temperature/wetting, i.e., the "Forming zone" in Fig. 3. The selection of the laser power and scan speed in the present investigation allowed the realisation of low, appropriate and high SLM energy inputs on WE43. The two extreme zones in the process map (Fig. 3) includes what are considered to be low, and high, energy inputs. When specimens were produced in the low energy input zone, they exhibited poor mechanical strength due to the extensive presence of process-induced pores and lack of fusion. At high energy inputs, a socalled loss (i.e., evaporation) of the $\mathrm{Mg}$ content occurred due to its low boiling point $\left(1090^{\circ} \mathrm{C}\right)$. Based on the process parameters window (Fig. 3), WE43 was SLMed using three sets of parameters: (i) Parameter 1: A laser power of $120 \mathrm{~W}$ and a scan speed of $960 \mathrm{~mm} / \mathrm{s}$, ( $\mathrm{ii}$ ) Parameter 2: $150 \mathrm{~W}$ and $1200 \mathrm{~mm} / \mathrm{s}$, and (iii) Parameter 3: $300 \mathrm{~W}$ and $1200 \mathrm{~mm} / \mathrm{s}$.

\subsection{Microstructural characterisation}

\subsubsection{WE43 in the as-cast condition}

To understand the unique microstructural features in the SLM prepared WE43, it was essential to consider the solidification microstructural characteristics of conventionally cast alloy counterpart. Herein, the microstructure of the cast WE43 (WE43MEO) was selected as a reference. The microstructure of the cast WE43 has been extensively studied in the literature $[31,32]$, and is also shown in Fig. 4. The SEM images shown in Figs. 4a-c present the microstructure of a cast WE43 consisting of solid-solution $\alpha-\mathrm{Mg}$ with a hexagonal structure (space group $6_{3} / m m c, a=0.32 \mathrm{~nm}, c=0.521 \mathrm{~nm}$ ). Based on SEM-EDXS analysis, $\alpha-\mathrm{Mg}$ grains in the case of the studied alloy also contained Y (0.3-0.5 at. \%), Nd (0.1-0.3 at. \%), Gd (0.1-0.15 at. \%) and $\mathrm{Zr}(0.02-0.8$ at. \%) and were surrounded by inter-dendritic regions (also called eutectic $\alpha$ ), which were rich in $\mathrm{Nd}$ (0.5-0.8 at. \%) and $\mathrm{Y}$ (1.1-1.4 at. \%).

The cast microstructure exhibited relatively large equiaxed grains with an average size of $90 \pm$ $12 \mu \mathrm{m}$, as seen in the EBSD analysis in Figs. $4 \boldsymbol{d}$ and $\boldsymbol{e}$. The microstructure of the cast alloy showed a near random crystallographic micro-texture with the intensity maxima dispersed rather uniformly due to the presence of the large grains, which is seen in the pole figures presented in Fig. $4 f$. Such a random crystallographic orientation of grains is a known characteristic of cast $\mathrm{Mg}$ alloys and have been reported on other $\mathrm{Mg}$-containing alloy systems [44]. Careful phase identification using SEM-EDXS and XRD revealed the typical precipitates (intermetallic phases) of WE43. 

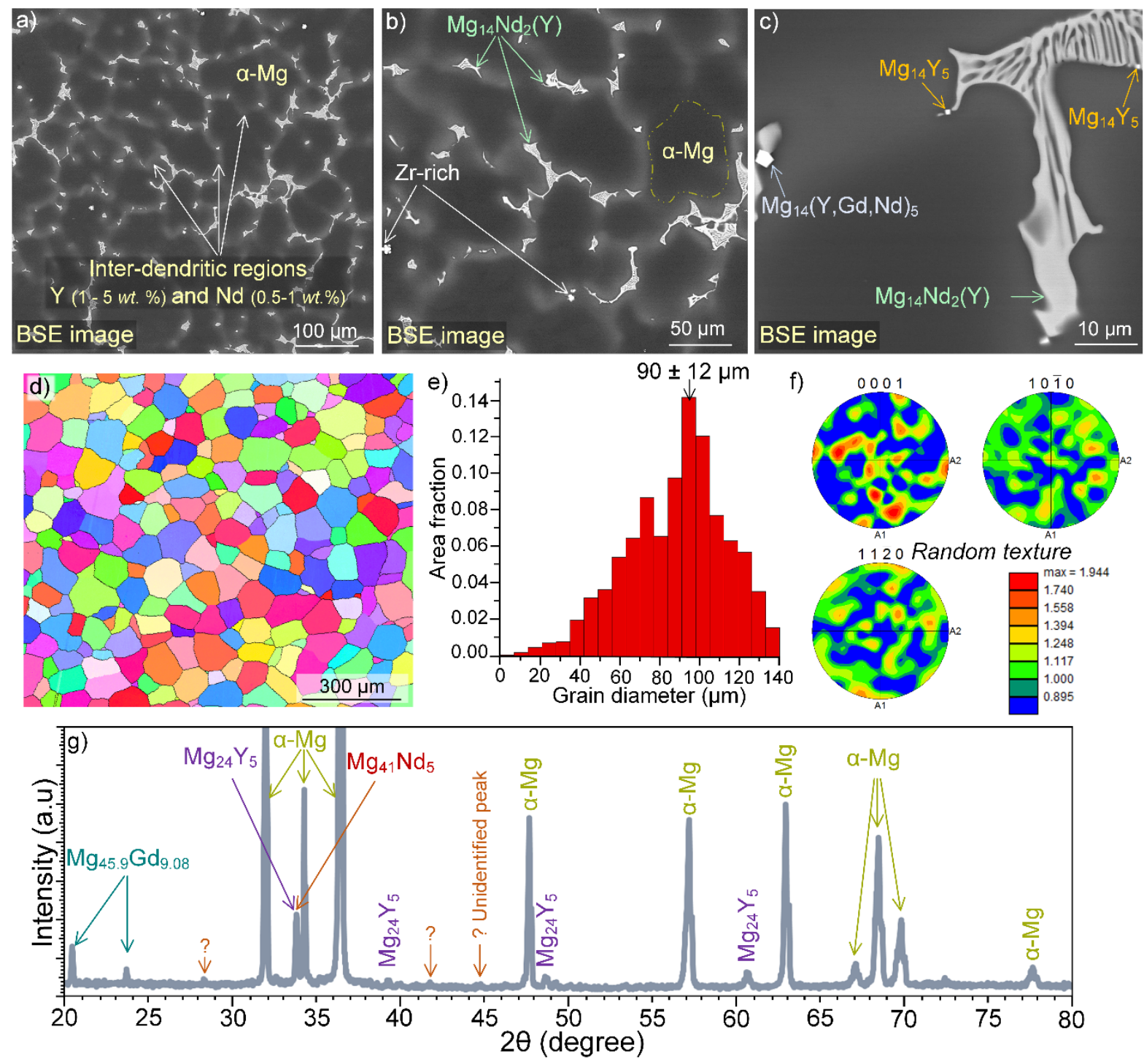

Figure 4. $(a-c)$ BSE-SEM micrographs revealing the typical microstructure of cast WE43 (the phases designated in Figs. $4 \boldsymbol{a}-\boldsymbol{c}$ were identified using EDXS), $(d-f)$ EBSD analysis revealing the grain structure and the random texture of the alloy, and $(g)$ XRD spectra showing the phases in WE43.

Intermetallic particles were thus rich in the main alloying elements ( $\mathrm{Zr}$ and the $\mathrm{REs}$ including $\mathrm{Y}, \mathrm{Nd}$, and in some cases, Gd) and were distributed discontinuously mainly along grain boundaries (inter-dendritic regions) and also inside the grain interiors. The main intermetallics include the equilibrium rod-shaped $\beta$-phase $\operatorname{Mg}_{14} \mathrm{Nd}_{2}(\mathrm{Y}, \mathrm{Gd})$, sub-micron faceted Y-rich particles $\left(\mathrm{Mg}_{14} \mathrm{Y}_{5}\right)$ along grain boundaries as well as $\mathrm{Mg}_{12} \mathrm{Nd}(\mathrm{Y}, \mathrm{Gd})$ particles with no preferential position in the alloy microstructure. It is noted that, based on Mg-Y-Nd ternary phase diagrams, the phases $\mathrm{Mg}_{24} \mathrm{Y}_{5}$ and $\mathrm{Mg}_{41} \mathrm{Nd}_{5}$ are anticipated and has also been reported in many studies [20, 45]. In addition, Zr-rich particles (the grain-refiner), the brightest particles could also be observed in the BSE-SEM images (Figs. $4 \boldsymbol{b}$ and $\boldsymbol{c}$ ). 


\subsubsection{WE43 in the as-SLM condition and after HIP and HT}

The solidification microstructure and preferred grain growth orientations of the SLM prepared samples were first investigated using EBSD (see the inverse pole figure EBSD maps in Fig. 5). The IPF maps corresponding to the as-SLMed samples (Parameters 1-3) are shown in Maps 13 in Fig. 5. The two sectioning planes viewed in both the $x-y$ and $x-z$ planes (the longitudinal and transversal sections) were both mapped by EBSD. An example is presented for the asSLMed sample (Parameter 1) in Map 1. The SLM-prepared samples revealed a refined microstructure compared to cast WE43 (the maps may be compared with the EBSD map of the cast WE43 in Fig. 3d), which was expected considering the high cooling rates inherent to SLM.

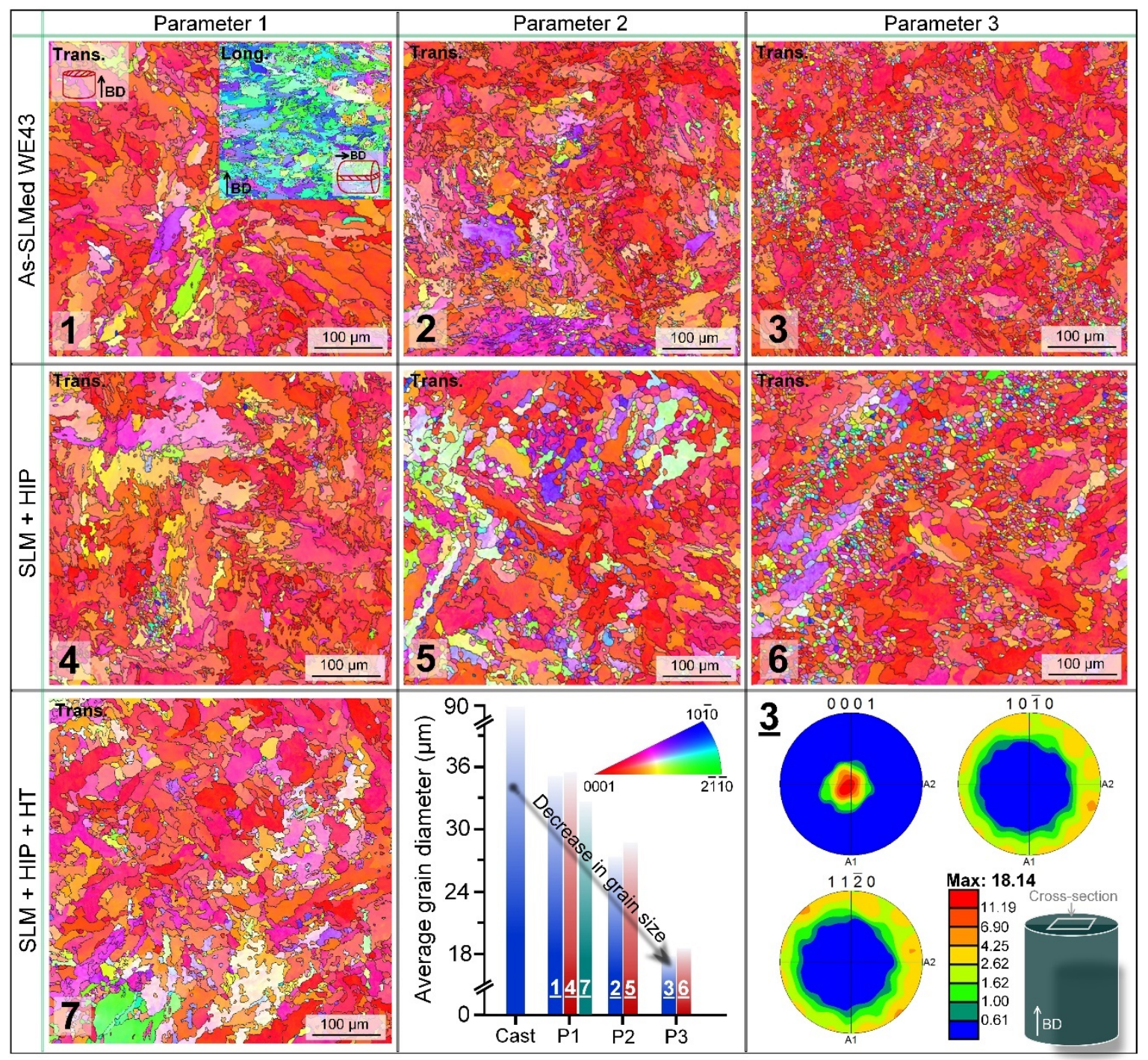

Figure 5. EBSD analysis of the samples in the as-SLMed, SLM + HIP and SLM + HIP + HT conditions. The figure also includes an example of pole figures corresponding to the EBSD map of SLM prepared sample fabricated using Parameter 3 (Map 3) exemplifying the strong basal texture of all SLM prepared WE43. The samples were extracted near top surface with $5 \mathrm{~mm}$ distance from top of the cylinders. 
The grains revealed irregular morphologies, corresponding the melt pool during SLM. It was evident that the specimen fabricated using Parameter 3 exhibited the finest grain structure with an average value of $\sim 17 \mu \mathrm{m}$ (with the cast WE43 showing an average grin size of $\sim 90 \mu \mathrm{m}$ ). The resultant microstructure of the sample with the finest microstructure exhibited numerous newly-nucleated recrystalised grains with an average grain size of $2.5 \pm 0.2 \mu \mathrm{m}$ (see Map 3 in Fig. 5). The occurrence of such "local" recrystallization phenomena in the SLM prepared WE43 has also been reported by Zumdick et al. [20].

The EBSD analysis showed that HIP and HIP + HT result in only an insignificant grain growth, indicating a rather stable microstructure of the SLM prepared samples, see the plot presenting the average grain sizes in Fig. 5. Furthermore, EBSD data implied that the fraction of low angle grain boundaries $\left(<15^{\circ}\right)$ decreased by HT (not shown). In contrast to the random grain orientation (EBSD analysis of cast WE43 in Figs. $3 \boldsymbol{d}$ and $\boldsymbol{f}$ ), a strong basal texture, wherein the $c$-axis of most grains were nearly parallel to the build direction (BD), was observed in all the SLM prepared specimens (Fig. 5). This could be ascribed to preferred grain growth orientation during SLM [20]. The texture intensity varied from 15-18.4 mrd (from random orientation) in the case of the as-SLM samples. The microstructure of samples in the HIP and HIP + HT conditions displayed the same texture but slightly weakened, decreasing to 10-13 mrd.

The microstructure and nanostructure of the SLM prepared specimens were characterised using SEM-EDXS, STEM-EDXS and XRD (Figs. 6-9). The results of the SEM investigations (Fig. 6) revealed the matrix of the as-SLMed samples was composed of $\alpha-\mathrm{Mg}$ grains, containing negligible amount of Y (0.1-0.2 at. \%) and $\mathrm{Nd}$ (0.05-0.1 at. \%), the values maybe compared with those of the cast microstructure, as described above. Thus, the $\alpha-\mathrm{Mg}$ grains (solid-solution matrix) in the microstructure of the SLM prepared WE43 was lean in Y and REs as compared with that of the cast alloy. Moreover, the microstructure of the alloy in the as-SLM condition exhibited no sign of eutectic $\alpha$ (inter-dendritic regions), but, a high density of flake-shaped particles (with a thickness of $<0.5 \mu \mathrm{m}$ ) as well as isolated/faceted particles rich in $\mathrm{Y}$ and $\mathrm{Nd}$. Compositional analysis using microanalysis employing EDXS mapping at two magnifications on the microstructure of the SLM prepared specimens are presented in Figs. 6d and $\boldsymbol{e}$. It was evident that the omnipresent flake-shaped features were oxides, consistent with the previous studies regarding SLM prepared WE43 [19, 20]. The flake-shaped features appeared to have two different compositions. The coarser flakes (Fig. 6 d) contained $\mathrm{Zr}$ and the main REs $(\mathrm{Nd}$ and $\mathrm{Y}$ ), while the finer oxygen-rich flakes exhibiting the highest aspect ratio among all the secondary phases in the microstructure contained only $\mathrm{Zr}$ and $\mathrm{Y}$, with no sign of $\mathrm{Nd}(\mathbf{F i g}$. $\mathbf{6 e}$ ). 


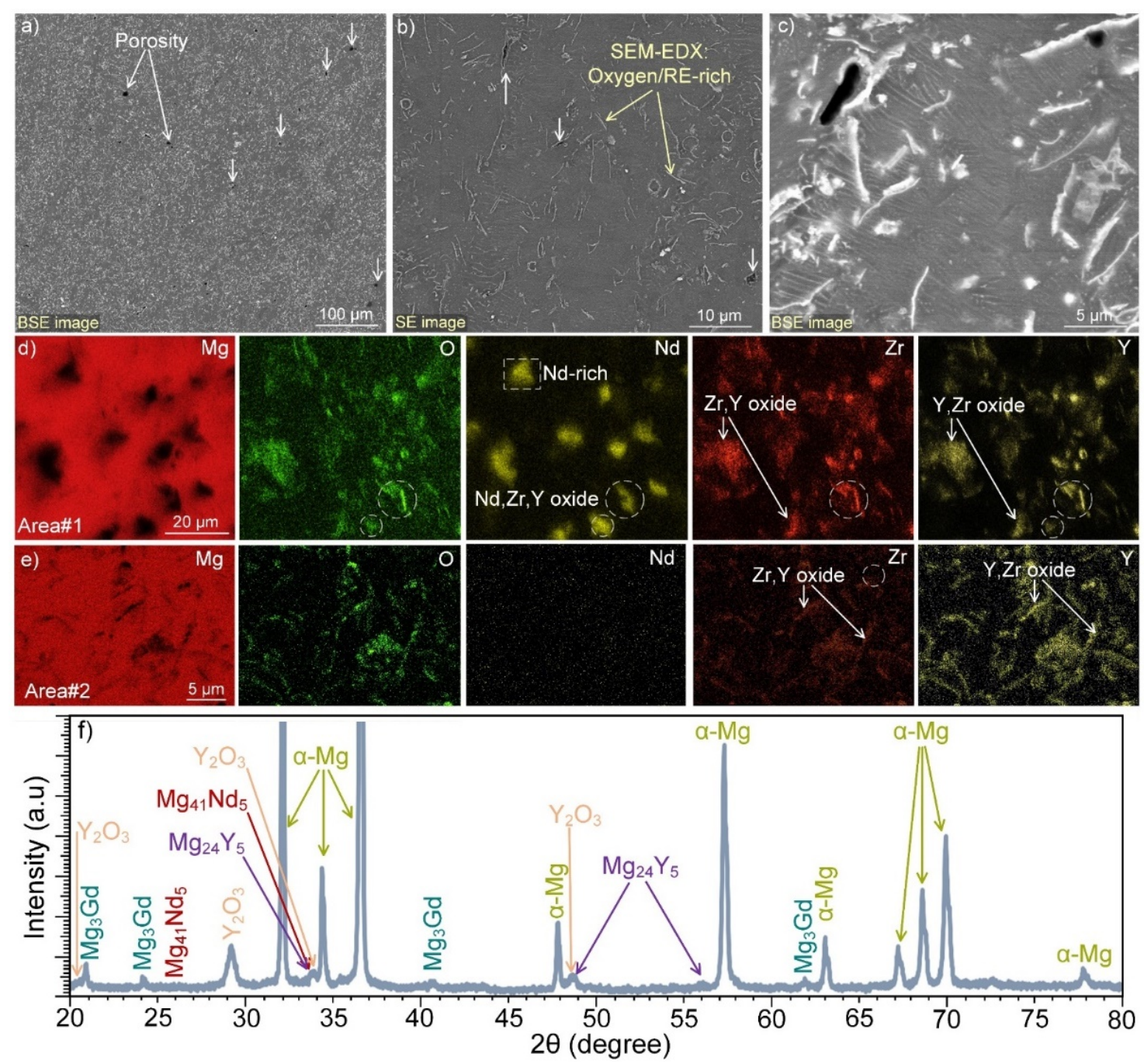

Figure 6. $(a-c)$ BSE-SEM micrographs showing the typical solidification microstructure of the asSLMed WE43 in the as-SLMed condition (Parameter 1), ( $d$ and $e$ ) EDXS maps acquired from the same material at two different magnifications, and $(g)$ XRD spectra showing the presence of various phases including intermetallics and oxygen-rich species in the as-SLMed WE43

In addition, there was ample evidence for the formation of $\mathrm{Nd}$-rich precipitates (see $\mathrm{Nd}$ map in Fig. 6d). Phase identification using XRD revealed strong evidence for the formation of $\mathrm{Y}_{2} \mathrm{O}_{3}$ and several peaks corresponding to $\mathrm{Mg}_{41} \mathrm{RE}_{4}$ and $\mathrm{Mg}_{24} \mathrm{Y}_{5}$. It is, however, cautioned that the two intermetallic types could not be identified using EDXS. Note that the XRD spectra of the SLM prepared sample is comparable with those reported in the literature [19, 20].

The STEM micrograph shown in Fig. 7a was acquired from one grain in the microstructure of the SLM prepared sample (fabricated using Parameter 1); see the selected area diffraction pattern (SADP) inserted in Fig. 7a. Thus, the SLM prepared material exhibited signs of cell boundaries corresponding to sub-micron cellular structures and dislocations (Figs. 7a-c), which is of no surprise considering the rapid solidification process during SLM. 
Compositional analysis using STEM-EDXS (Figs. $7 c$ and $\boldsymbol{d}$ ) revealed that the cell boundaries were enriched in $\mathrm{Nd}$ and $\mathrm{Y}$. In some cases, the cell boundaries seen in Fig. $7 c$ showed a chemical composition close to that of $\mathrm{Mg}_{14} \mathrm{Nd}_{2} \mathrm{Y}$. There was also strong evidence for the formation of various oxygen-rich phases including $\mathrm{Y}_{2} \mathrm{O}_{3}$ (see the oxygen and $\mathrm{Y}$ maps in Fig. 7d), Nd-Y-O (see the EDXS spectrum in Fig. 7e) and Y-Nd-Zr-O particles distributed mainly inside the grain interiors. The microstructure also contained fine particles with a chemical composition close to that of $\mathrm{Mg}_{41} \mathrm{Nd}_{4}$, in agreement with the XRD data of the as-SLMed material (Fig. 6f). These particles appeared as globular features (with a low aspect ratio, as compared with oxide phases) and were distributed rather uniformly across the alloy grains.
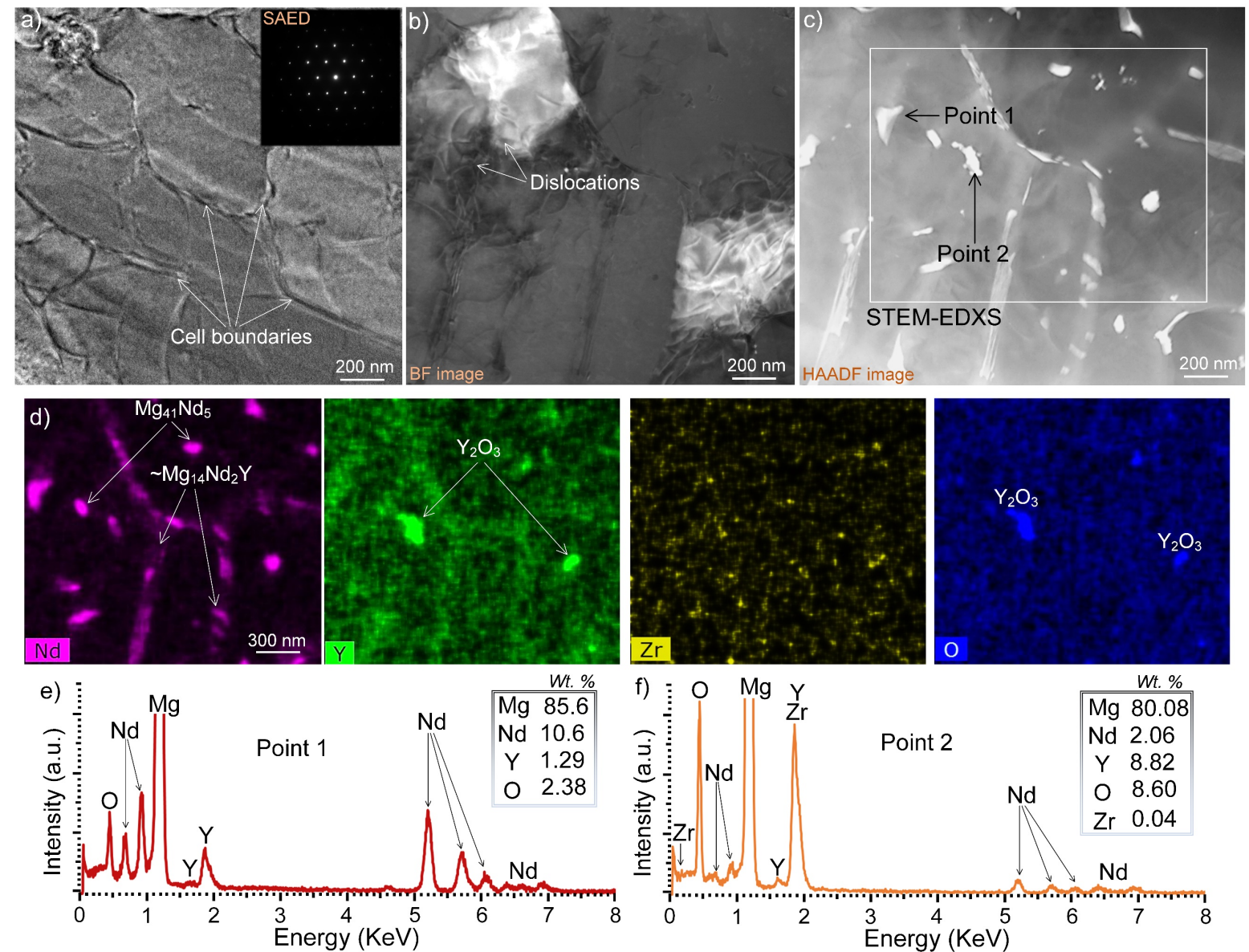

Figure 7. $(a-c)$ STEM micrographs revealing dislocations and cell boundaries in the microstructure of the as-SLM WE43 (Parameter 1), (d) STEM-EDXS elemental maps acquired from the boxed area in Fig. $7 c$, $(e$ and $f)$ EDXS point analysis from the two areas denoted by the arrows in Fig. $7 c$.

The microstructure of the SLM prepared WE43 in the HIP and HIP+HT conditions are described in Fig. 8. It is noted that HIP removed (nearly) all AM-induced microscopic pores, which were described above for the as-SLMed condition (compare Figs. $6 \boldsymbol{b}$ and $\boldsymbol{c}$ with Figs. 
$\mathbf{8} \boldsymbol{a}-\boldsymbol{f}$ ). However, microstructural analysis revealed that the characteristic morphology of the flake-shaped oxide particles in the as-SLMed microstructure (Figs. $6 \boldsymbol{b}$ and $\boldsymbol{c}$ ) remained unchanged, which can clearly be observed in the SE-SEM micrographs in Figs. 8a-c. The ZrY-Nd -rich oxide phases were also present in the microstructure of the HIP + HT specimen (Figs. 8d-f), but slightly to a smaller extent. A distinct difference in the microstructure of the specimens in the as-SLM and HIP + HT conditions was dissolution of the minuscule Nd- and Y-rich particles (compare the STEM-EDXS data in Figs. $\mathbf{7 d}$ and $\mathbf{8 g}$ ). Thus, $\alpha$-Mg grains in the microstructure of the HIP + HT specimens became slightly richer in Y (0.25-0.34 at. \%) and Nd (0.2-0.38 at. \%). Furthermore, compositional analysis using STEM-EDXS revealed that HIP and HIP + HT altered the elemental segregation at the alloy cell boundaries, with $\mathrm{Nd}$ as the only trace element in the grain boundaries (compare Fig. 7d with Fig. 8g).

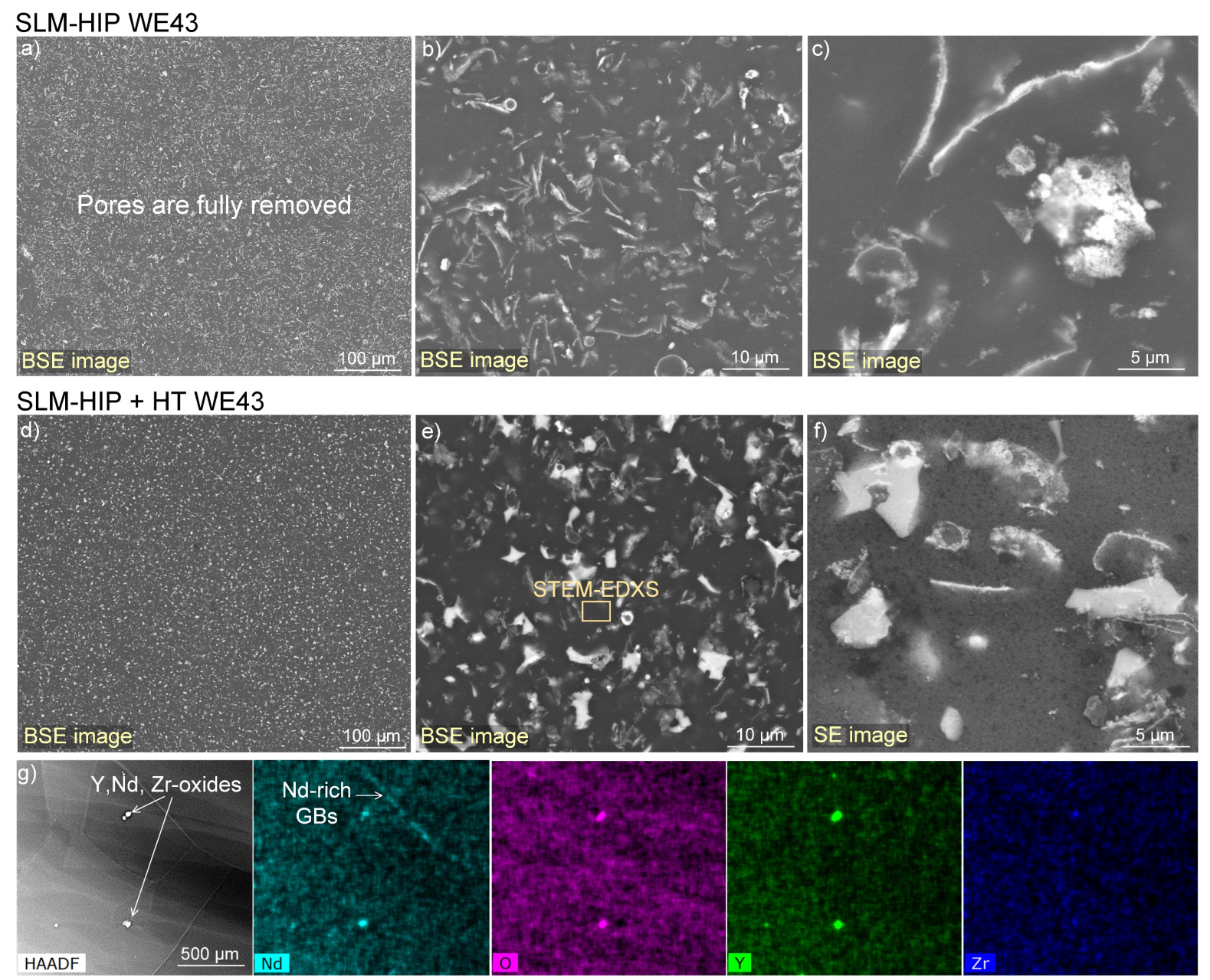

Figure 8. $(a-c)$ BSE-SEM micrographs revealing the microstructure of the sample in the SLM prepared WE43 after HIP, (d-f) BSE-SEM micrographs revealing the microstructure of the same sample after HT, and $(g)$ STEM-EDXS mapping acquired from the SLM prepared sample in the HIP + HT condition. 
In summary, assessment using optical microscopy, SEM, SEM-EDXS, EBSD and XRD revealed that the solidification microstructures of the samples in the as-SLMed condition (fabricated using Parameters 1, 2 and 3, see Fig. 3) were similar, exhibiting no sign of macroscopic and only a negligible evidence for microscopic porosity (see Figs. $6 \boldsymbol{a}$ and $\boldsymbol{b}$ ).

\subsubsection{Defect analysis in SLM prepared samples}

Incorporation of oxygen into the microstructure of the SLM prepared samples (i.e., the formation of oxygen-containing particles) is a persistent issue in SLM of Mg alloys, as was observed herein in all the conditions (Figs. 6-8) as well as in the literature $[19,20,25]$. In addition to the oxygen-rich particles with the flake-shaped morphology shown in Figs. 6, occasionally, areas consisting of agglomerated oxide particles enriched in $\mathrm{Y}(\mathrm{Zr}$ and $\mathrm{Nd})$ and with a faceted morphology could be observed in the microstructure of the SLM prepared samples (of all conditions); an example is presented in Figs. $9 \boldsymbol{a}$ and $\boldsymbol{b}$.

The oxide phases in as-SLMed specimens produced via Parameter 1-3 displayed two distinct morphologies; flake-shaped with high aspect ratio (Figs. 6 and 8) and faceted/rectangular (Fig. 9a). To explore the origins of the enhanced oxygen content, the microstructure of a defective regions was examined (Fig. 9c). Note that oxides (and hydroxides) affect the wettability of the molten pool during SLM ([43]) and thus such an investigation is crucial. In the area viewed in Fig. 9c, SLM-induced defects including keyhole or lack of fusion, metallurgical (gas) pores and unmelted particles were noticeable. While sub-micron sized gas pores were homogenously distributed in the microstructure, larger defects with irregular morphologies, known as lack of fusion, were preferentially located around unmelted powder particles (Fig. 9c). There have been several explanations on the causes and formation of such pores in the SLM prepared alloys such as $(i)$ carbon and hydrogen contaminations on the powder [46], (ii) internal gas pore from the powder [47], and (iii) gas entrapment during SLM [48]. The flake-shaped oxides were sourced from the raw alloy powder (the SEM image inserted in Fig. 9c). Occasionally, even whole powder particles with their whole oxide shell could be found in the microstructure. The oxide shells and the oxygen-rich flakes on the surface of the powder were wetted by the molten $\mathrm{Mg}$, suggestively fragmented, and became trapped in the alloy microstructure during the solidification. Note that the surface to volume ratio of the powder is orders of magnitude larger than that of bulk alloys and thus the surface composition of the powders plays a decisive role in the microstructure of the SLM prepared alloys. It is thus suggested that oxidation of powder surfaces is a major influence factor for controlling microstructure of SLM prepared WE43. 


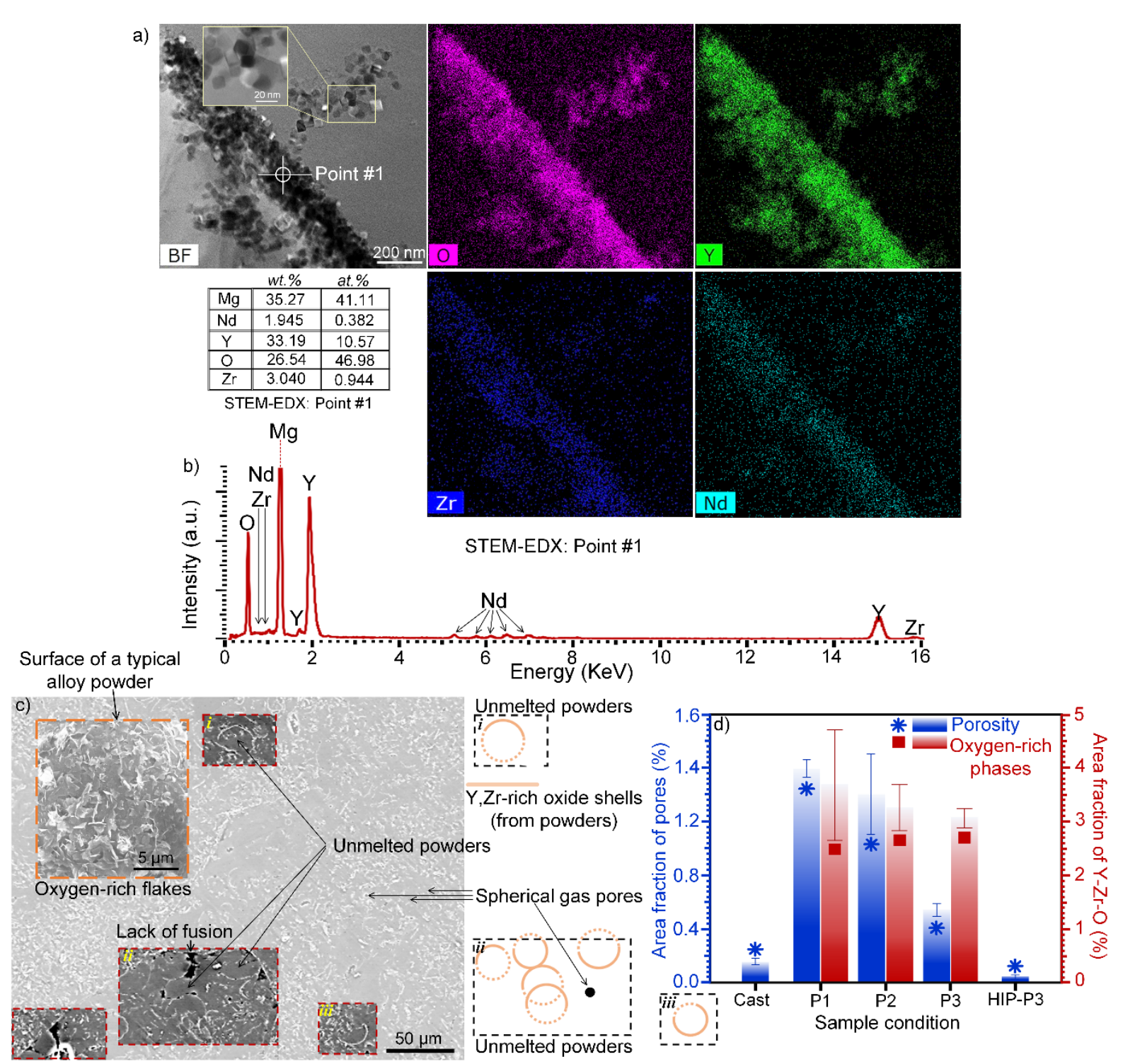

Figure 9. $(a$ and $b$ ) STEM-EDXS map and point analysis from an oxide-rich area in the as-SLMed sample (Parameter 3) after HIP + HT, (c) SEM micrograph from a defective region in the as-SLMed sample (Parameter 1) as well as a SE-SEM image revealing the surface of the WE43 powder that is covered by oxygen-rich flakes, and $(d)$ statistical data on the fraction of pores and oxygen-rich flakes as function of process parameter and post-processing.

Statistical analysis was carried out to understand the differences in the fraction of defects and oxygen-rich phases in the as-SLMed, SLM+ HIP and SLM + HIP + HT samples. The effect of process parameters and post-processing (SLM + HIP and SLM + HIP + HT) on porosity and oxide phases is depicted in Fig. 9d. It was evident that defect (including metallurgical (gas) pores and keyhole or lack of fusion) density is dependent on laser power and scan speed, see also the process map in Fig. 3. Thus, the sample fabricated using Parameter 1 showed the highest and the sample fabricated using Parameter 3 (higher energy input) exhibited the lowest fraction of defects with an area fraction of $1.4 \%$ and $0.5 \%$, respectively. These values maybe 
compared with that of the cast alloy $(\sim 0.15 \%)$, also presented in Fig. 9d. The higher porosity fraction in the sample fabricated by Parameter 1 as compared with that of Parameter 3 has to be attributed to the insufficient deposition of energy as a consequence of the lower heat input.

According to the literature, this results in partial melting of powder incorporating into the melt pool and the voids between such particles could coalesce and increase the overall pore density. The fraction of porosity in the SLM prepared samples expectedly reached $<0.1 \%$ in the HIP condition, which could also be seen in the SEM micrographs (compare e.g., Figs. $\mathbf{6} \boldsymbol{b}$ and $\boldsymbol{c}$ with Figs. 8a-c), which agrees well with the study performed by Gangireddy et al. [19]. In contrast, statistical analysis indicated little influence of process parameters (laser power and scan speed) on the formation of the flake-shaped oxide phases (as shown in Figs. 6 and 8), when the scatters are considered. Thus, the fraction of oxides in the samples fabricated using Parameters 1-3, varied between 3.1 to $4.9 \%$.

\subsection{The electrochemical response of the SLM prepared alloys}

Open circuit potential (OCP) evolution of the samples in the cast, as-SLMed, HIP and HIP + HT conditions was examined in $0.1 \mathrm{M} \mathrm{NaCl}$ for a period of 10 minutes, as displayed in Fig. 10a. The SLM prepared samples (in the as-SLMed and post-processed conditions) exhibited a more positive OCP than the cast material. In conjunction with the OCP measurements, potentiodynamic polarisation testing was vital as it provides information on the key reaction kinetics (anodic and cathodic reaction rates) of the SLM prepared specimens. The polarisation curves of the specimens exposed in $0.1 \mathrm{M} \mathrm{NaCl}$ is presented in Fig. $10 a$.

The cathodic and anodic polarization curves reveal the kinetics cathodic hydrogen evolution (HER) and anodic dissolution of the samples, respectively. The fitted corrosion parameters including corrosion current density $\left(\mathrm{j}_{\text {corr }}\right)$ and corrosion potentials $\left(\mathrm{E}_{\text {corr }}\right)$, calculated using the Tafel extrapolation of the potentiodynamic polarisation curves [7], are presented in Fig. 10b. It is noted that the polarisation curves of the SLM prepared sample fabricated using Parameter 2 and the sample in the HIP condition were similar to that of Parameter 1 and 3 and thus they are not shown in Fig. 10b. Inspection of the polarisation curves in Fig. $10 b$ reveals that the SLM prepared samples exhibited an enhanced cathodic HER kinetics as compared to the cast alloy. The anodic reaction kinetics of the SLM prepared samples showed a very low anodic Tafel slope and little to no region of passivity. 

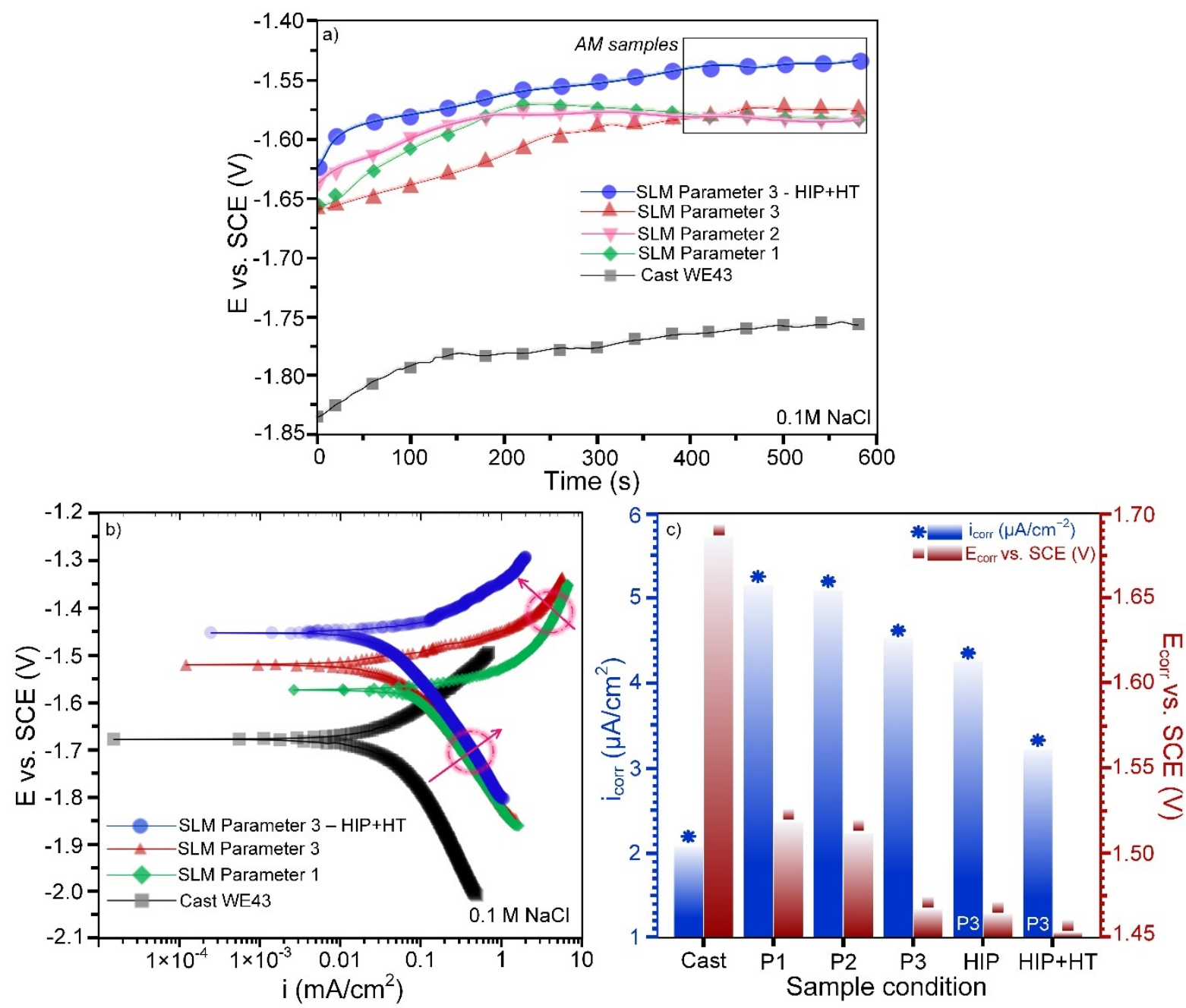

Figure 10. (a) Open circuit potential of WE43 in the cast, as-SLMed, SLM + HIP + solutionsing HT conditions in $0.1 \mathrm{M} \mathrm{NaCl}$ for up to $10 \mathrm{~min},(b)$ potentiodynamic polarisation curves of the same specimens tested in Fig. 10a following exposure to $0.1 \mathrm{M} \mathrm{NaCl}$ for a conditioning period, and $(c)$ the quantitative data on corrosion potential and corrosion current density acquired from the potentiodynamic polarisation analysis (Fig. 10b).

The anodic branch of the polarisation curve of the SLM prepared sample in the HIP + HT condition exhibited a shift to the left, concomitant with reduced anodic kinetics. The differences in the polarisation curves was reflected in the corrosion current density and the corrosion potential values (Fig. 10c). The cast WE43 showed the lowest corrosion current density $\left(2 \pm 0.35-2.4 \pm 0.18 \mu \mathrm{A} / \mathrm{cm}^{2}\right)$ and the as-SLMed WE43 (Parameters 1-3) exhibited the highest corrosion current densities ( 4.4 to $5.1 \pm 0.67 \mu \mathrm{A} / \mathrm{cm}^{2}$ ). It was also notable that while HIP alone had little impact on the reaction kinetics of the SLM prepared samples, HIP + HT effectively reduced the corrosion current density. 
Electrochemical impedance spectroscopy (EIS) measurements were also performed in order to characterise the differences in the time dependant electrochemical response of the specimens under investigation. The corresponding Nyquist plots of the samples in the (i) cast, (ii) asSLMed (Parameter 3) and (iii) SLM prepared (Parameter 3) + HIP + HT are depicted in Figs. 11a-c. Electrochemical equivalent circuit models were proposed (Figs. 11d-f) in order to fit the EIS data (see the fitted results in Table 2) and hence to illuminate the corrosion characteristics of cast WE43 and SLM prepared WE43.

The Nyquist plots of cast WE43 following $1 \mathrm{~h}$ and $24 \mathrm{~h}$ OCP immersion were characterised by two capacitive loops, irrespective of the immersion time (Fig. 11a). The high frequency capacitive loop represents the characteristic of alloy-electrolyte interface and is used to determine charge transfer resistance $\left(\mathrm{R}_{c t}\right)$ and double layer capacitance $\left(\mathrm{C}_{d l}\right)$. However, resistance $\left(\mathrm{R}_{f}\right)$ and capacitance $\left(\mathrm{C}_{f}\right)$ of the film are determined by medium frequency capacitive loop. Frequency dependent impedance response of the equivalent circuit for cast WE43 (Fig. 11d) can be described using the following equation:

$$
|Z|=R_{s}+\frac{1}{j \omega C_{d l}+\frac{1}{R_{c t}+\frac{1}{\frac{1}{R_{f}}+j \omega C_{f}}}}
$$

where $R_{s}$ is the solution resistance, which is ideally expected to be similar in all conditions, $\omega$ is the angular frequency ( $=2 \pi f$, where $f$ is frequency) and $j=\sqrt{-1}$. The Non-ideal (i.e., nonDebye) capacitance is represented by a constant phase element $(\mathrm{Q})$ - which is related to capacitance via the following relationship:

$$
\mathrm{C}=\mathrm{Q}^{\frac{1}{\mathrm{n}}} \mathrm{R}^{\frac{1-\mathrm{n}}{\mathrm{n}}}
$$

where $n$ is the dispersion coefficient, a real number that could vary between 0 and 1 .

In stark contrast to the observed impedance response of cast WE43, the Nyquist plots of the SLM prepared specimens in the as-SLMed and SLM + HIP + HT conditions presented a decreasing trend in impedance with immersion time (Figs. 11a and $\boldsymbol{d}$ ). Following $1 \mathrm{~h}$ immersion (conditioning at open circuit), the SLM prepared samples exhibited a high frequency capacitive loop and a medium-to-low frequency capacitive loop that extended into positive region of imaginary component $\left(\mathrm{Z}_{\mathrm{I}}\right)$ and decreasing real component $\left(\mathrm{Z}_{\mathrm{R}}\right)$ with decreasing frequency. Such an "inductive loop" is a common phenomenon in Mg alloys [49, 50]. Nevertheless, the observed three-loop circuit can be described as the following equation: 


$$
|Z|=R_{s}+\frac{1}{j \omega C_{d l}+\frac{1}{R_{c t}+\frac{1}{\frac{1}{R_{f}}+j \omega C_{f}}}+\frac{1}{R_{L}+j \omega L}}
$$

where $\mathrm{R}_{\mathrm{L}}$ and $\mathrm{L}$ denote the resistance and inductance associated with induction loop. The SLM prepared specimen after HIP + HT exhibited higher charge transfer as well as higher film resistance than the as-SLMed specimen. After $24 \mathrm{~h}$ of OCP immersion, medium frequency capacitive loop (representing the film characteristics) was disappeared in both cases (i.e., in the as-SLMed and SLM + HIP + solutionising HT conditions). The total impedance response presented in Equation 3 can be modified by removing the film component from the circuit (if $R_{f}=0$ then $\frac{1}{\frac{1}{R_{f}}+j \omega C_{f}}=0$ ) that arrives at:

$$
|Z|=R_{s}+\frac{1}{j \omega C_{d l}+\frac{1}{R_{t}}+\frac{1}{R_{L}+j \omega L}}
$$

In general, it was evident that cast WE43 (Figs. 11 $a$ and $\boldsymbol{d}$ ) exhibited an increasing trend in impedance with immersion time, meaning that diffusional processes (from the electrolyte towards the alloy/oxide interface) was limited by the formation of a quasi-protective corrosion layer. Although film resistance of cast WE43 slightly decreased after $24 \mathrm{~h}$ of OCP immersion, charge transfer resistance increased significantly (Table 2). This suggests that overall corrosion performance of cast WE43 improved with immersion time, in contrast to SLM prepared WE43. In the SLM prepared specimens (Figs. $11 b$ and $\boldsymbol{c}$ ), the EIS curves exhibited no sign for medium frequency capacitive loop, which indicates the time dependent degradation of the quasiprotective corrosion layer during immersion test. Furthermore, it can be seen in the Table 2 that charge transfer as well as film resistance of the SLM prepared samples were lower than that of their conventionally cast alloy counterpart, which could be attributed to the inductive loop after $1 \mathrm{~h}$ of immersion (suggesting the occurrence of localized corrosion at OCP itself).

Table 2. An example of fitting to typical EIS data using the equivalent circuits in Figs. 11d-f.

\begin{tabular}{lllllll}
\hline & Cast WE43 & \multicolumn{2}{c}{ SLMed P3 } & \multicolumn{2}{l}{ SLMed P3 (HIP+HT) } \\
\hline & $1 \mathrm{~h}$ & $24 \mathrm{~h}$ & $1 \mathrm{~h}$ & $24 \mathrm{~h}$ & $1 \mathrm{~h}$ & $24 \mathrm{~h}$ \\
\cline { 2 - 7 } $\mathrm{R}_{\mathrm{s}}\left(\Omega \mathrm{cm}^{2}\right)$ & 64 & 72.5 & 68.1 & 70.4 & 75.2 & 78.2 \\
$\mathrm{Q}_{\mathrm{dl}}\left(\mu \mathrm{F} \mathrm{cm}{ }^{-2} \mathrm{~s}^{(\mathrm{n}-1)}\right)$ & 12 & 13.9 & 73.5 & 205.1 & 6.6 & 139.5 \\
$\mathrm{n}_{\mathrm{dl}}$ & 0.9 & 0.9 & 0.7 & 0.9 & 0.9 & 0.9 \\
$\mathrm{R}_{\mathrm{ct}}\left(\Omega \mathrm{cm}^{2}\right)$ & 2337 & 3790.7 & 32.5 & 54.5 & 81.9 & 83.2 \\
$\mathrm{Q}_{\mathrm{f}}\left(\mu \mathrm{F} \mathrm{cm}^{-2} \mathrm{~s}^{(\mathrm{n}-1)}\right)$ & 360 & 269.2 & 79.6 & - & 20.6 & - \\
$\mathrm{n}_{\mathrm{f}}$ & 0.7 & 0.7 & 0.9 & - & 0.9 & - \\
$\mathrm{R}_{\mathrm{f}}\left(\Omega \mathrm{cm}^{2}\right)$ & 1303 & 903.6 & 91 & - & 356.7 & - \\
$\mathrm{L}\left(\mathrm{H} \mathrm{cm}{ }^{-2}\right)$ & - & - & 2157.8 & 8145.3 & 5770.3 & 6251.5 \\
$\mathrm{R}_{\mathrm{L}}\left(\Omega \mathrm{cm}^{2}\right)$ & - & - & 134.2 & 64.3 & 335.4 & 90.8 \\
\hline
\end{tabular}



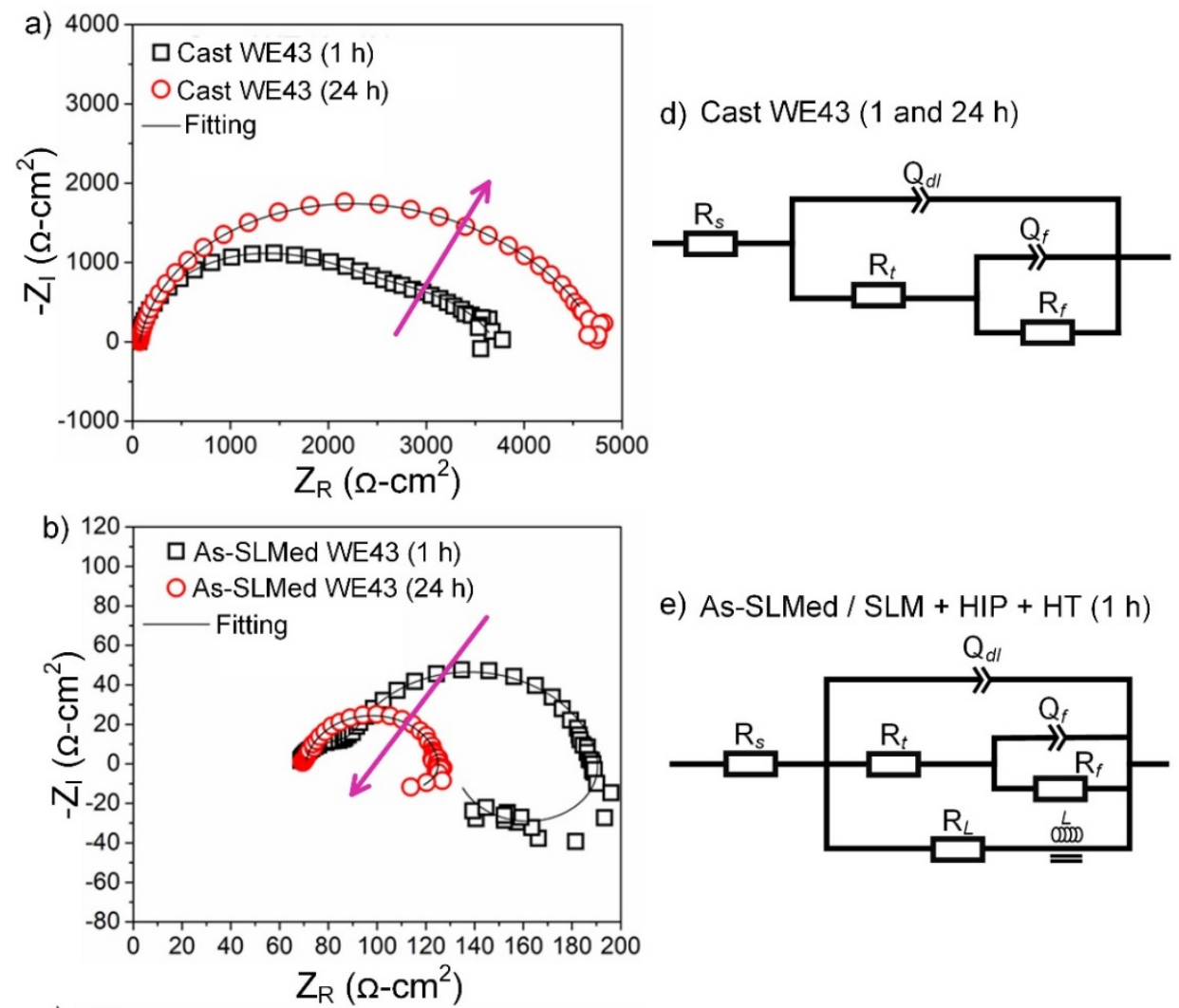

e) As-SLMed / SLM + HIP + HT (1 h)
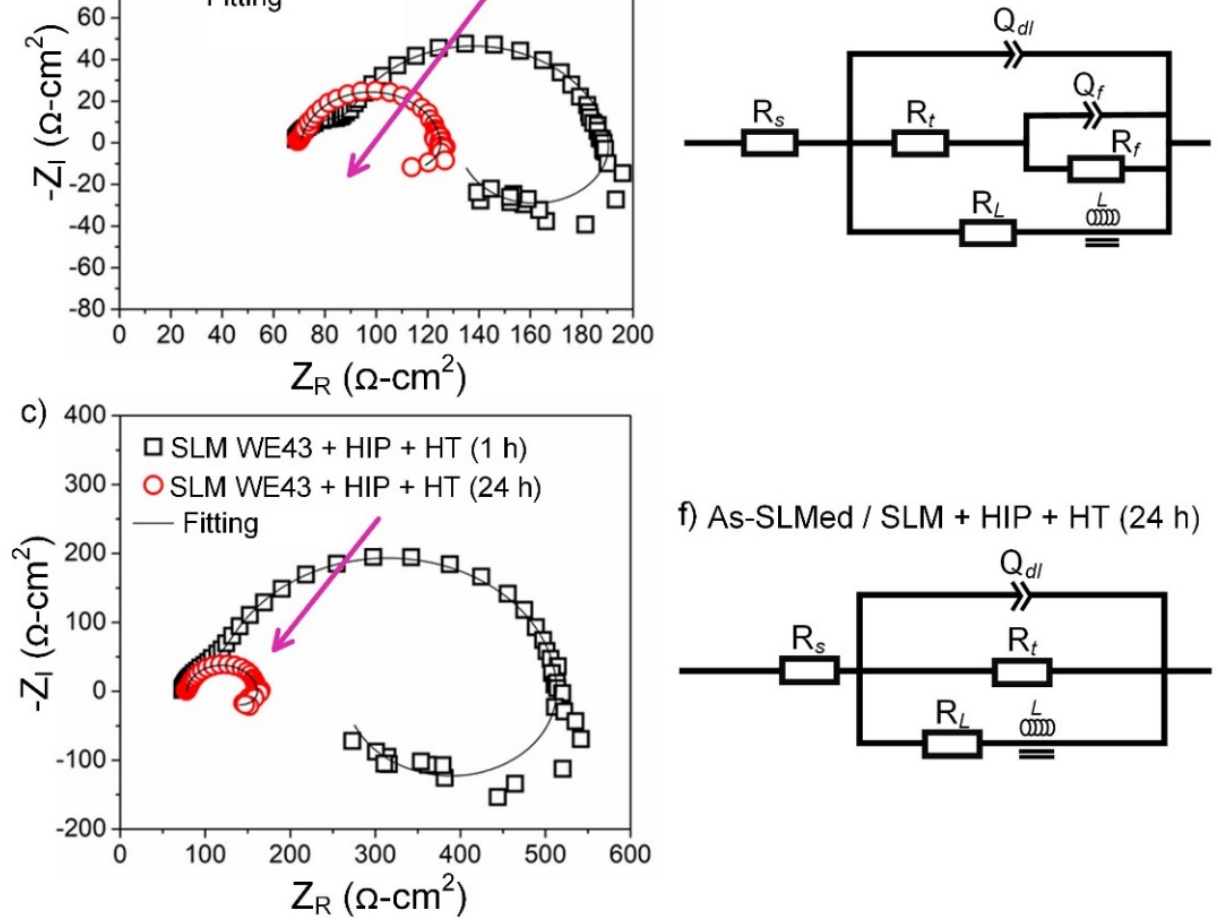

Figure 11. Nyquist plots of WE 43 in the: $(a)$ cast, $(b)$ as-SLMed, and (c) SLM + HIP + HT conditions. The equivalent circuits representing WE43 in the: $(d)$ cast, $(e)$ as-SLMed and SLM + HIP + HT exposed to $\mathrm{NaCl}$ for $1 \mathrm{~h}$, and $(f)$ as-SLMed and SLM + HIP + HT conditions exposed to $\mathrm{NaCl}$ for $24 \mathrm{~h}$. Note that all the SLM prepared specimens studied here was manufacturing using Parameter 3.

Whilst the electrochemical experiments including potentiodynamic polarisation (Fig. 10) and EIS (Fig. 11) allow quantification of electrochemical kinetics, they are instantaneous in nature, and thus, supplementation with physical testing can provide a more accurate assessment of corrosion performance. The surface evolution and corrosion morphology of the as-SLMed sample (Parameter 3) for different times is depicted in Fig. 12a. In the early stages of immersion $(<1 \mathrm{~h})$, many hydrogen bubbles were formed on the surface of the as-SLMed WE43 (Figs. 12ai and aii), indicating the cathodic activity of Zr- and Y-rich intermetallics. 
As immersion time increased, rather extensive hydrogen streams started to appear at some sites, implying a substantial release of hydrogen gas. With further immersion, these localized corrosion sites developed and further intensified, as designated by the arrows in Fig. 12a (the image showing the surface state after $10 \mathrm{~h}$ immersion in Fig. 12aiii). This was concomitant with the formation of visually "dark" corrosion products. Strong hydrogen stream evolution could then be clearly seen at the fronts of the dark corrosion products. After longer immersion, the dark corroded areas expanded further and merged such as the whole specimen surface.
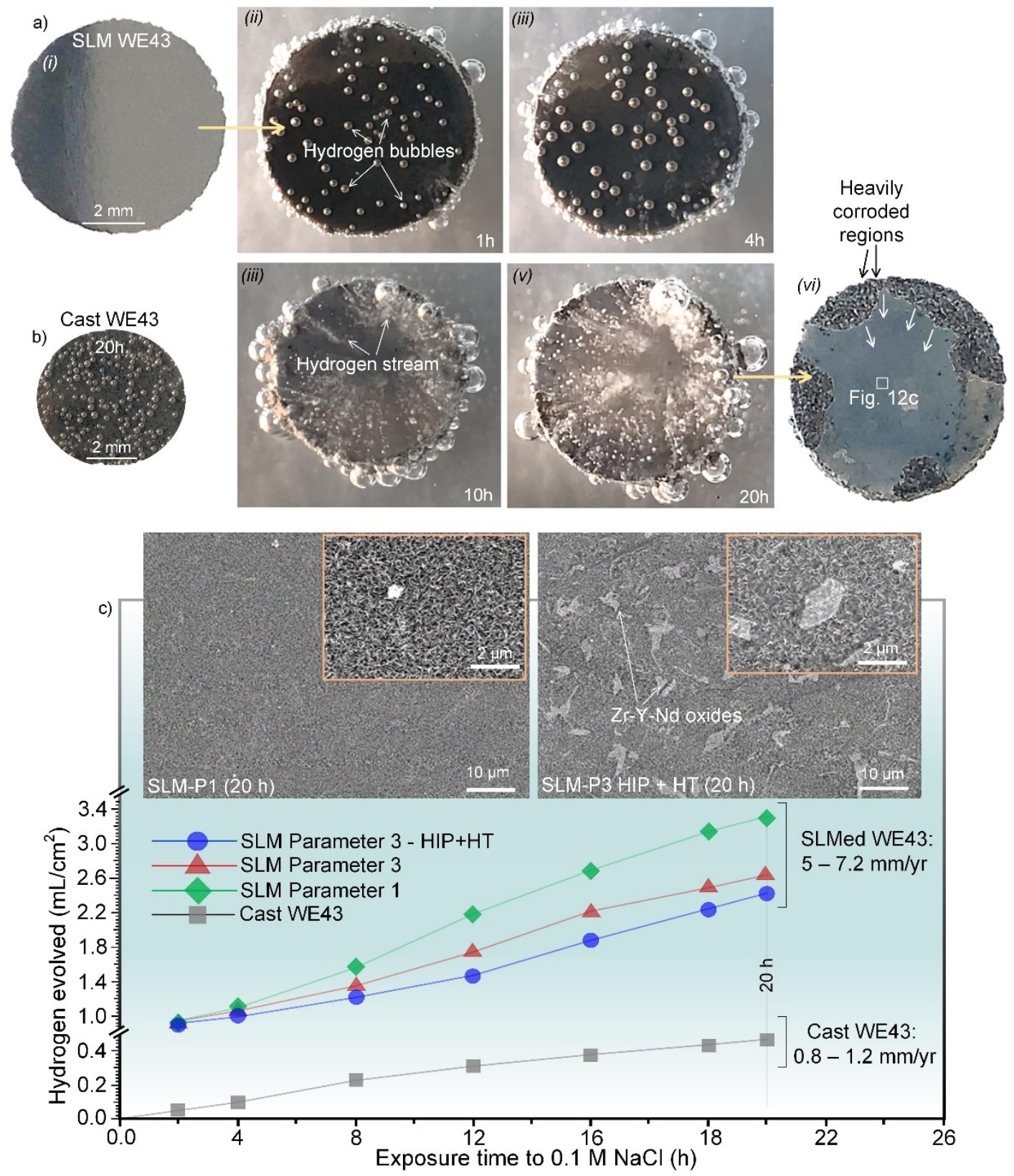

Figure 12. (a) Time-series photographs showing the corrosion evolution of the as-SLMed sample (Parameter 3) during exposure to $0.1 \mathrm{M} \mathrm{NaCl}$ solution for $20 \mathrm{~h},(b)$ an image showing the surface of the cast WE43 during exposure to $0.1 \mathrm{M} \mathrm{NaCl}$ solution, and (c) hydrogen evolved, corrosion rates and post immersion SEM of the as-SLMed (Parameter 1) and SLM + HIP + HT specimens. 
The observation on the extensive release of hydrogen bubbles and hydrogen stream was somewhat consistent for the SLM prepared samples in all the conditions (as-SLMed, SLM + HIP and SLM + HIP + HT). Based on in-situ observations (Fig. 12a), in comparison with cast WE43 (see the image showing the alloy surface $20 \mathrm{~h}$ immersion in Fig. 12b), the production of hydrogen gas from the surface of the as-SLMed WE43 (Fig. 12av) was greater.

The principal cathodic reaction accompanying the dissolution of $\mathrm{Mg}$ alloys in aqueous electrolytes is water reduction, resulting in the evolution of hydrogen gas; and therefore, the collection of hydrogen is a direct proxy to the rate of the cathodic partial corrosion reaction. The hydrogen evolution of the cast and the SLM prepared samples during immersion in $0.1 \mathrm{M}$ $\mathrm{NaCl}$ solution is presented in Fig. 12c. In all cases, the hydrogen evolution rate increased with immersion time owing to an increase in the catholically active surface area. The SLM prepared samples (in all the conditions) showed a greater hydrogen volume (an accordingly higher corrosion rates) than the cast WE43 released during $20 \mathrm{~h}$ of immersion in $0.1 \mathrm{M} \mathrm{NaCl}$. It was noticeable that the cathodic hydrogen evolution reaction (HER) kinetics for SLM prepared samples in the as-SLMed condition tested herein decreased in the following order of SLMParameter $1>$ SLM-Parameter $3>$ SLM-Parameter 3 (HIP + HT), though, the difference between the samples were not significant, in accordance with Figs. 10 and 11.

The hydrogen collection results were also confirmed by SEM morphological investigation (the images inserted in Fig. 12c). Note that the SEM micrographs were acquired not from the regions suffering heavy corrosion, i.e., accumulation of coarse corrosion products, but from the regions of seemingly uncorroded regions (the boxed area in Fig. 12avi). At enhanced magnifications, the surface of the SLM prepared samples was covered by a uniform film of fine and porous features, which was somewhat similar with what is commonly observed when $\mathrm{Mg}$ and its alloys are immersed in $\mathrm{NaCl}$ solution. Compositional analysis using SEM-EDXS revealed that these areas (and also the heavily corroded regions) contains $40-50$ at. $\% \mathrm{Mg}, 50$ 55 at. $\% \mathrm{O}$ and $2-3.5$ at. $\% \mathrm{Cl}$, indicating the rough mixture of $\mathrm{Mg}(\mathrm{OH})_{2}, \mathrm{MgO}$ and $\mathrm{MgCl}_{2}$. In the regions covered by the thinner layer of corrosion products, the SEM images in Fig. 12c the alloying elements ( $\mathrm{Zr}$ and $\mathrm{REs}$ including $\mathrm{Nd}$ and $\mathrm{Y}$ ) could also be detected. While the composition and morphology of the corrosion products were not the focus of this research, the attention is drawn to the difference in the corrosion performance of the SLM prepared samples in the as-SLMed and SLM + HIP + HT conditions. 


\section{Discussion}

The research in the area of AM-Mg alloys has recently been directed towards biomedical applications, as indicated in Fig. 1. Recent degradation experiments in dulbecco's modified eagle medium (DMEM) [18] and simulated body fluid (SBF) [25] in conjunction with compression tests have demonstrated that SLM prepared WE43 exhibit a relatively low hydrogen release and a relatively small reduction of mechanical stability with time. While additively manufactured $\mathrm{Mg}$ implants have not yet been commercialised, the example of the compression screw MAGNEZIX ${ }^{\circledR}$ CS (Syntellix AG, Germany) as the first WE43 implant for application in humans (Fig. 1) is notable [35, 51]. There have been few investigations on the use of such Mg-based implants in chevron osteotomies for hallux valgus corrective surgery [52], reporting significant functional outcomes, which were maintained for a period of at least 3 to 6 months postoperative. The authors of cited clinical studies utilising the newly manufactured Mg implants have however noted "signs of early corrosion with subsequent (bone) disintegration" [52]. The recent studies have thus specified a need for further considerations on "corrosion effects during healing and radiographic appearance" and "a fastrelease of hydrogen gas", which is considered to be non-toxic but could cause local tissue and bone displacement via subcutaneous gas cavities [52,53]. Thus, understanding of the corrosion process is of great importance in future implementation of the SLMed Mg-based alloys, certainly not only in the biomedical but also structural applications.

From the results presented above, it was evident that there are key differences in the microstructure of the SLM prepared WE43 (in the as-SLM, SLM + HIP and SLM + HIP + HT conditions) and its conventionally cast alloy counterpart (Fig. 4 vs. Figs. 5-9) in terms of chemistry and characteristic morphology (size, density and distribution) of microstructural features. Such differences are important to understand as the microstructure and chemistry of the surface dictate corrosion of $(\mathrm{Mg})$ alloys [7]. The as-SLMed WE43 exhibited a finer grain structure than cast WE43 (17 vs. $90 \mu \mathrm{m}$; see the EBSD maps in Figs. $4 c$ and 5), which is considered beneficial in the context of mechanical stability, as demonstrated elsewhere [1820]. The microstructure is highly textured which also accords with a recent study on microstructure of a SLM prepared WE43 [26].

In the as-SLMed WE43, oxides comprising Y, Zr and REs revealing (mainly) a flake-shape morphology were abundant and homogenously distributed in the microstructure (Figs. 6a-c), which was not the case in the cast microstructure. The oxides in the microstructure of the SLM prepared alloys were found to originate (mainly) from the starting powder (Fig. 9c). This is 
expected considering the strong affinity of the main alloying elements in WE43 for oxygen. Of the various elements, $\mathrm{Y}$ and $\mathrm{Zr}$ have remarkably high affinities for oxygen, with standard Gibbs free energy of formation of their oxides to be -1817 and $-1135 \mathrm{~kJ} / \mathrm{mol}$, respectively, which are amongst the highest values of all elements and lower than that of $\mathrm{Mg}(-569 \mathrm{~kJ} / \mathrm{mol})$ [54].

A significant observation in the microstructure of the SLM-prepared WE43 was Zr segregation to REs (Fig. 6d), which has never been reported in cast WE43. In the SLM prepared WE43 under investigation here, the formation of oxides resulted in $\alpha-\mathrm{Mg}$ grains (solid-solution matrix) becoming lean in Y (and Nd). In addition, eutectic $\alpha$ (rich in Y and Nd; Fig. $4 \boldsymbol{a}$ and [55]) in the matrix of cast WE43, which covered $8 \pm 2.5 \%$ of the cast alloy surface, was not found in the as-SLMed WE43 (Figs. 6a-c). The unique characteristics of the SLM prepared alloys, which were found to be rather consistent, regardless of the process condition (i.e., Parameters 1-3; representing the medium to high heat input zones), have to be attributed to $(i)$ the powderisation of the alloy, and (ii) the rapid solidification inherent to SLM.

The surface of SLM prepared WE43 was cathodically more active than the cast WE43 in 0.1 $\mathrm{M} \mathrm{NaCl}$ solution (Figs. 10-12); which appeared to be a consistent trend in the SLM prepared specimens in the as-SLM, HIP and HIP + HT conditions. The differences in the electrochemical and corrosion response of the SLM prepared and cast WE43 can be rationalised by the observed microstructural differences. The distribution of the main alloying elements ( $\mathrm{Zr}, \mathrm{Y}$ and REs) is decisive in determining the corrosion performance of WE-series Mg alloys as this governs the anodic and cathodic kinetics of the matrix and (second phase) particles [56, 57]. As such, when $\mathrm{Y}$ is confined to the solid solution (in $\alpha-\mathrm{Mg}$ grains and/or in eutectic $\alpha$ ), the dissolution rate of matrix is decreased and propagation of corrosion is slowed down [55, 57]. This is because the alloying elements present in the solid-solution matrix ( $\mathrm{Y}$ in WE-series Mg alloys) have been suggested to incorporate into the quasi-passive corrosion layers, accountable for their increased corrosion resistance $[57,58]$. The slight improvement in the corrosion resistance of the SLM prepared WE43 in the HIP + solutionising HT condition may also be due to the increase in the $\mathrm{Y}$ and RE content of the solid-solution matrix, arising from the dissolution of Y-and RE-rich nanoparticles, as was shown using STEM-EDXS (Fig. 8g). Moreover, the Zr-rich intermetallics in the microstructure of WE series have been found to exhibit the most positive Volta potential differences with respect to $\mathrm{Mg}$ matrix among all second phases present, and therefore, they effectively serve as local cathodes, promoting localised corrosion [59]. 


\section{Conclusions}

The microstructure, electrochemical response and corrosion resistance of selective laser melted (SLMed) WE43 in as-SLMed (with three different parameter settings), hot isostatic pressing $(\mathrm{SLM}+\mathrm{HIP}), \mathrm{SLM}+\mathrm{HIP}+$ solutionising heat treatment $(\mathrm{HT})$ were studied herein and compared with conventionally cast WE43. The main findings of the present study are summarised as follows:

1. The SLM method resulted in a unique microstructure revealing fine grains with a strong [0001] texture along the building direction. Under proper laser parameters $(\mathrm{P}=300 \mathrm{~W}$ and $\mathrm{v}=1200 \mathrm{~mm} / \mathrm{s}$ ), the SLM prepared WE43 was found to exhibit a negligible fraction of metallurgical and process-induced defects. It was also noted that HIP treatment (at $520^{\circ} \mathrm{C}, 103 \mathrm{MPa}$ for $4 \mathrm{~h}$ ) is an effective approach to eliminate the process-induced defects, thus achieving an (nearly) fully dense specimens.

2. The SLM prepared WE43 exhibited a substantially different microstructure relative to cast WE43. As the principal microstructural feature, a high density of fine oxide flakes rich in $\mathrm{Y}$ and $\mathrm{Nd}$ were observed to distribute uniformly in the microstructure of the SLM prepared alloys (in all conditions). Significantly, EDXS microanalysis showed that $\mathrm{Zr}$ segregated to REs forming Zr-, Y-, Nd-oxides, in contrast to cast WE43.

3. Solutionsing treatment at $525^{\circ} \mathrm{C}$ for $8 \mathrm{~h}$ resulted in dissolution of $\mathrm{Y}$ - and Nd-rich nanoparticles $\left(\mathrm{Mg}_{41} \mathrm{RE}_{4}\right.$ and $\left.\mathrm{Mg}_{24} \mathrm{Y}_{5}\right)$, whilst no effect of $\mathrm{HT}$ was noted in the fraction and chemical composition of the oxide flakes observed in the as-SLMed WE43.

4. Electrochemical characterisation using potentiodynamic polarisation testing, impedance spectroscopy and hydrogen collection in $0.01 \mathrm{M} \mathrm{NaCl}$ revealed increase in cathodic kinetics of the SLM prepared WE43 as compared to cast WE43. It was proposed that the rather pronounced re-distribution of $\mathrm{Zr}$ and $\mathrm{Y}$ can be considered accountable for the enhanced cathodic activity of the SLM prepared WE43.

The strong affinities of $\mathrm{Y}$ and $\mathrm{Zr}$ for oxygen promote the formation of oxides during powdersiation. The two next critical research directions which merit important work in the future include designing new alloy chemistries explicitly suited for SLM (to retard the cathodic kinetics upon the Mg-rich matrix) as well as modifying the powderisation process that could supress oxidation of alloy powder during atomisation. 


\section{- Data Availability:}

The raw/processed data required to reproduce these findings cannot be shared at this time due to technical or time limitations.

\section{- Declaration of Competing Interest:}

The authors declare that they have no known competing financial interests or personal relationships that could have appeared to influence the work reported in this paper.

\section{- Acknowledgments:}

ME and NM thank the Swedish Research Council and the Royal Swedish Academy of Engineering Sciences for the financial support. The authors acknowledge use of facilities within the Monash Centre for Electron Microscopy (MCEM), the Monash Centre for Additive Manufacturing (MCAM) and The Monash X-ray Platform (MXP). 


\section{-References:}

1. W.E. Frazier, Metal Additive Manufacturing: A Review, Journal of Materials Engineering and Performance, J. Mater. Eng. Perform. 23 (2014) 1917-1928.

2. S. Vunnam, A. Saboo, C. Sudbrack, T.L. Starr, Effect of powder chemical composition on the as-built microstructure of 17-4 PH stainless steel processed by selective laser melting, Addit. Manuf. 30 (2019) 100876. https://doi.org/10.1016/j.addma.2019.100876

3. Q. Han, Y. Gu, R. Setchi, F. Lacan, R. Johnston, S.L. Evans, S. Yang, Additive manufacturing of high-strength crack-free Ni-based Hastelloy X superalloy, Addit. Manuf. 30 (2019), 100919. https://doi.org/10.1016/j.addma.2019.100919

4. T. Majumdar, N. Eisenstein, J.E. Frith, S.C. Cox, N. Birbilis, Additive Manufacturing of Titanium Alloys for Orthopedic Applications: A Materials Science Viewpoint, Adv. Eng. Mater. 20 (2018) 1800172 https://doi.org/10.1002/adem.201800172

5. N.T. Aboulkhair, M. Simonelli, L. Parry, I. Ashcroft, C. Tuck, R. Hague, 3D printing of Aluminium alloys: Additive Manufacturing of Aluminium alloys using selective laser melting, Prog. Mater. Sci. 106 (2019) 100578 https://doi.org/10.1016/j.pmatsci.2019.100578

6. S.K.Kairy, B. Rouxel, J.Dumbre, J. Lamb, T.J. Langan, T.Dorin, N.Birbilis, Simultaneous improvement in corrosion resistance and hardness of a model $2 \mathrm{xxx}$ series Al-Cu alloy with the microstructural variation caused by Sc and Zr additions, Corros. Sci. 158 (2019) 108095. https://doi.org/10.1016/j.corsci.2019.108095

7. M. Esmaily, J.E. Svensson, S. Fajardo, N. Birbilis, G.S. Frankel, S. Virtanen, R. Arrabal, S. Thomas, L.G. Johansson, Fundamentals and advances in magnesium alloy corrosion, Prog. Mat. Sci. 89 (2017) 92-193. https://doi.org/10.1016/j.pmatsci.2017.04.011

8. L. Wu, F. Feyerabend, A.F. Schilling, R. Willumeit-Römer, B.J.C. Luthringer, Effects of extracellular magnesium extract on the proliferation and differentiation of human osteoblasts and osteoclasts in coculture, Acta Biomater. 27 (2015) 294-304. https://doi.org/10.1016/j.actbio.2015.08.042

9. W. Xu, N. Birbilis, G. Sha, Y. Wang, J.E. Daniels, Y. Xiao, M. Ferry, A high-specific-strength and corrosionresistant magnesium alloy, Nat. Mater. 14 (2015) 1229-1235. https://doi.org/10.1038/nmat4435

10. Y.M. Yan, O. Gharbi, A. Maltseva, X.B. Chen, Z.R. Zeng, S.W. Xu, W.Q. Xu, P. Volovich, M. Ferry, N. Birbilis, Investigating the Structure of the Surface Film on a Corrosion Resistant Mg-Li(-Al-Y-Zr) Alloy, CORROSION 75 (2019) 80-89. https://doi.org/10.5006/2995

11. J.H. Nordlien, S. Ono, N. Masuko, K. Nisancioglu, Morphology and structure of oxide films formed on MgAl alloys by exposure to air and water, J. Electrochem. Soc. 143 (1996), pp. 2564-2572. doi: 10.1149/1.1837048

12. M. Esmaily, D.B. Blücher, R.W. Lindström, J.E. Svensson, L.G. Johansson, The influence of $\mathrm{SO}_{2}$ on the corrosion of magnesium and Mg-Al alloys, J. Electrochem. Soc, 162 (2015) C260-C269. https://10.1149/2.0801506jes

13. R.L. Liu, M.F. Hurley, A. Kvryan, G. Williams, J.R. Scully, N. Birbilis, Controlling the corrosion and cathodic activation of magnesium via microalloying additions of Ge, Sci. Rep. 6 (2016) 28747. https://doi.org/10.1038/srep28747

14. S. Tang, T. Xin, W. Xu, D. Miskovic, G. Sha, Z. Quadir, S. Ringer, K. Nomoto, N. Birbilis, M. Ferry, Precipitation strengthening in an ultralight magnesium alloy, Nat. Commun. 10 (2019) 1003. https://doi.org/10.1038/s41467-019-08954-z

15. Z. Hu, R.L. Liu, S.K. Kairy, X. Li, H. Yan, N. Birbilis, Effect of Sm additions on the microstructure and corrosion behavior of magnesium alloy AZ91, Corros. Sci. 149 (2019) 144-152. https://doi.org/10.1016/j.corsci.2019.01.024 
16. R.L. Liu, Z.R. Zeng, J.R. Scully, G. Williams, N. Birbilis, Simultaneously improving the corrosion resistance and strength of magnesium via low levels of $\mathrm{Zn}$ and Ge additions, Corros. Sci. 140 (2019) 18-29. https://doi.org/10.1016/j.corsci.2018.06.027

17. N.T. Kirkland, N. Birbilis, M.P. Staiger, Assessing the corrosion of biodegradable magnesium implants: a critical review of current methodologies and their limitations, Acta Biomater. 8 (2012) 925-936 https://doi.org/10.1016/j.actbio.2011.11.014

18. A. Kopp, T. Derra, M. Müther, L. Jauer, J.H. Schleifenbaum, M. Voshage, O. Jung, R. Smeets, N. Kröger, Influence of design and postprocessing parameters on the degradation behavior and mechanical properties of additively manufactured magnesium scaffolds. Acta Biomater. $98 \quad$ (2019) 23-35. https://doi.org/10.1016/j.actbio.2019.04.012

19. S. Gangireddy, B. Gwalani, K. Liu, E.J. Faierson, R.S. Mishra, Microstructure and mechanical behavior of an additive manufactured (AM) WE43-Mg alloy, Addit. Manuf. $26 \quad$ (2019) 53-64. https://doi.org/10.1016/j.addma.2018.12.015

20. N.A. Zumdick, L. Jauer, L.C. Kersting, T.N. Kutz, J.H. Schleifenbaum, D. Zandera, Additive manufactured WE43 magnesium: A comparative study of the microstructure and mechanical properties with those of powder extruded and as-cast WE43, Mater. Charact. 147 (2019) 384-397. https://doi.org/10.1016/j.matchar.2018.11.011

21. B. Zhang, H. Liao, C. Coddet, Effects of processing parameters on properties of selective laser melting Mg-9\% Al powder mixture, Mater. Des. 34 (2012) 753-758. https://doi.org/10.1016/j.matdes.2011.06.061

22. K. Wei, M. Gao, Z. Wang, X. Zeng, Effect of energy input on formability, microstructure and mechanical properties of selective laser melted AZ91D magnesium alloy, Mater. Sci. Eng. A 611 (2014) 212-222. https://doi.org/10.1016/j.msea.2014.05.092

23. C. Shuai, Y. Yang, P. Wu, X. Lin, Y. Liu, Y. Zhou, P. Feng, X. Liu, S. Peng, Laser rapid solidification improves corrosion behavior of Mg-Zn-Zr alloy, J. Alloys Comp. $691 \quad$ (2017) 961-969. https://doi.org/10.1016/j.jallcom.2016.09.019

24. M. Salehi, S. Maleksaeedi, M.A.B Sapari, M.L.S. Nai, G.K. Meenashisundaram, M. Gupta, Additive manufacturing of magnesium-zinc-zirconium (ZK) alloys via capillary-mediated binderless three-dimensional printing, Mater. Des. 169 (2019) 107683. https://doi.org/10.1016/j.matdes.2019.107683

25. Y. Li, J. Zhou, P. Pavanram, M.A. Leeflang, L.I. Fockaert, B. Pouran, N. Tümer, K.U. Schröder, J.M.C. Mol, H.Weinans, H. Jahr, A.A. Zadpoora, Additively manufactured biodegradable porous magnesium, Acta Biomater. 67 (2018) 378-392. https://doi.org/10.1016/j.actbio.2017.12.008

26. F. Bär, L. Berger, L. Jauer, G. Kurtuldu, R. Schäublin, J.H. Schleifenbaum, J.F. Löffler, Laser additive manufacturing of biodegradable magnesium alloy WE43: A detailed microstructure analysis, Acta Biomater. 98 (2019) 36-49. https://doi.org/10.1016/j.actbio.2019.05.056

27. C.C. Ng, M.M. Savalani, H.C. Man, I. Gibson, Layer manufacturing of magnesium and its alloy structures for future applications, Virtual Phys. Prototyping, 5 (2010) 13-19. 10.1080/17452751003718629

28. C.C. Ng, M.M. Savalani, M.L. Lau, H.C. Man, Microstructure and mechanical properties of selective laser melted magnesium, Appl. Surf. Sci., 257 (2011) 7447-7454. 10.1016/j.apsusc.2011.03.004

29. M. Salehi, S. Maleksaeedi, H. Farnoush, M.L.S. Nai, G.K. Meenashisundaram, M. Gupta, An investigation into interaction between magnesium powder and Ar gas: Implications for selective laser melting of magnesium, Powder Technol. 333 (2018) 252-261. https://doi.org/10.1016/j.powtec.2018.04.026

30. K.U. Kainer, Magnesium Alloys and Their Applications, Wiley Online Library (2000). 
31. T. Rzychoń, A. Kiełbus, Microstructure of WE43 casting magnesium alloy, J. Achiev. Mater. Manuf. Eng. 21 (2007) 31-34.

32. I.P. Moreno, T.K. Nandy, J.W. Jones, J.E. Allison, T.M. Pollock, Microstructural stability and creep of rareearth containing magnesium alloys, Scr. Mater. 48 (2003) 1029-1034. https://doi.org/10.1016/S13596462(02)00595-X

33. V. Manakari, G. Parande, M. Gupta, Selective Laser Melting of Magnesium and Magnesium Alloy Powders: A Review, Metals 7 (2017) 2-35. doi:10.3390/met7010002

34. L. Jauer, W. Meiners, S. Vervoort, C. Gayer, N.A. Zumdick, D, Zander, Selective laser melting of magnesium alloys, European congress and exhibition on powder metallurgy. European PM Conference Proceedings (2016).

35. R. Biber, J. Pauser, M. Brem, H.J. Bail, Bioabsorbable metal screws in traumatology: A promising innovation, Trauma Case Reports 8 (2017) 11-15. https://doi.org/10.1016/j.tcr.2017.01.012

36. C. Taltavull, B. Torres, A.J. López, P. Rodrigo, E. Otero, J. Rams, Selective laser surface melting of a magnesium-aluminium alloy, Mater. Lett. 85 (2012) 98-101. https://doi.org/10.1016/j.matlet.2012.07.004

37. M.M. Farag, H.S. Yun, Effect of gelatin addition on fabrication of magnesium phosphate-based scaffolds prepared by additive manufacturing system, Mater. Lett. 132 (2014) 111-115. https://doi.org/10.1016/j.matlet.2014.06.055

38. D. Hu, Y. Wang, D. Zhang, L. Hao, J. Jiang, Z. Li, Y. Chen, Experimental investigation on selective laser melting of bulk net-shape pure magnesium, Mater. Manuf. Process. 30 (2015) 1298-1304. https://doi.org/10.1080/10426914.2015.1025963

39. M. Esmaily, M. Shahabi-Navid, J.E. Svensson, M. Halvarsson, L. Nyborg, Y. Cao, L.G. Johansson, Influence of temperature on the atmospheric corrosion of the magnesium alloy AM50, Corros. Sci. 90 (2015) 420-433. https://doi.org/10.1016/j.corsci.2014.10.040

40. N. Mortazavi, M. Esmaily, M. Halvarsson, The capability of Transmission Kikuchi Diffraction technique for characterizing nano-grained oxide scales formed on a FeCrAl stainless steel, Mater. Lett. 147 (2015) $42-45$. https://doi.org/10.1016/j.matlet.2015.02.008

41. M. Shahabi-Navid, M. Esmaily, J.E. Svensson, M. Halvarsson, L. Nyborg, Y. Cao, L.G. Johansson, NaClinduced atmospheric corrosion of the MgAl alloy AM50-the influence of $\mathrm{CO}_{2}$, J. Electrochem. Soc. 161 (2014) C277-C287. doi: 10.1149/2.088405jes

42. C.L.A. Leung, S. Marussi, R.C. Atwood, M. Towrie, P.J. Withers, P.D. Lee, In situ X-ray imaging of defect and molten pool dynamics in laser additive manufacturing, Nat. Commun. 9 (2018) 1355. doi:10.1038/s41467-01803734-7

43. C.L.A. Leung, S. Marussi, M. Towrie, R.C. Atwood, P.J. Withers, P.D. Lee, The effect of powder oxidation on defect formation in laser additive manufacturing, Acta Mater. 166 (2019) 294-305. https://doi.org/10.1016/j.actamat.2018.12.027

44. M. Esmaily, M. Shahabi-Navid, N. Mortazavi, J.E. Svensson, M. Halvarsson, M. Wessén, A.E.W. Jarfors, L.G. Johansson, Microstructural characterization of the Mg-Al alloy AM50 produced by a newly developed rheocasting process, Mater. Charact. 95 (2014) 50-64. https://doi.org/10.1016/j.matchar.2014.06.001

45. J. Groebner, Magnesium - neodymium - yttrium, L. Aller, I. Appenzeller, B. Baschek, K. Butler, C. De Loore, H. Duerbeck, M. El Eid, H. Fink, T. Herczeg, T. Richtler (Eds.), Landolt-Börnstein: Numerical Data and Functional Relationships in Science and Technology-New Series (1996) 343-350.

46. N.T. Aboulkhair, N.M. Everitt, I. Ashcroft, C. Tuck, Reducing porosity in AlSi10Mg parts processed by selective laser melting, Addit. Manuf. 1 (2014) 77-86.

https://doi.org/10.1016/j.addma.2014.08.001 
47. C. Qiu, C. Panwisawas, M. Ward, H.C. Basoalto, J.W. Brooks, M.M. Attallah, On the role of melt flow into the surface structure and porosity development during selective laser melting, Acta Mater. 96 (2015) 72-79. https://doi.org/10.1016/j.addma.2014.08.001

48. F. Léonard, S. Tammas-williams, P.B. Prangnell, I. Todd, P.J. Withers, Assessment by X-ray CT of the effects of geometry and build direction on defects in titanium ALM parts, Conf. Ind. Comput. Tomogr (2012) 85-93. http://www.ndt.net/article/ctc2012/papers/91.pdf

49. A.D. King, N. Birbilis, J.R. Scully, Accurate electrochemical measurement of magnesium corrosion rates; A combined impedance, mass-loss and hydrogen collection study, Electrochim. Acta. 121 (2014) 394-406. doi:10.1016/j.electacta.2013.12.124.

50. V. Shkirskiy, A.D. King, O. Gharbi, P. Volovitch, J.R. Scully, K. Ogle, N. Birbilis, Revisiting the electrochemical impedance spectroscopy of magnesium with online inductively coupled plasma atomic emission spectroscopy, ChemPhysChem 16 (2015) 536-539. https://doi.org/10.1002/cphc.201402666

51. J.M. Seitz, A. Lucas, M. Kirschner, Magnesium-based compression screws: a novelty in the clinical use of implants, JOM 68 (2016) 1177-1182.

52. C. Plaass, S. Ettinger, L. Sonnow, S. Koenneker, Y. Noll, A. Weizbauer, J, Reifenrath, L, Claassen, K, Daniilidis, C. Stukenborg- Colsman, H. Windhagen, Early results using a biodegradable magnesium screw for modified chevron osteotomies, J. Orthop. Res. 34 (2016) 2207-2214. https://doi.org/10.1002/jor.23241

53. H. Windhagen, K. Radtke, A. Weizbauer, J. Diekmann, Y. Noll, U. Kreimeyer, Biodegradable magnesiumbased screw clinically equivalent to titanium screw in hallux valgus surgery: short term results of the first prospective, randomized, controlled clinical pilot study, Bio. Medical. Eng. OnLine 12 (2013). http://dx.doi/10.1186/1475-925X-12-62

54. N. Mortazavi, C. Geers, M. Esmaily, V. Babic, M. Sattari, K. Lindgren, P. Malmberg, B. Jonsson, M. Halvarsson, J.E. Svensson, I. Panas, L.G. Johansson, Interplay of water and reactive elements in oxidation of aluminaforming alloys, Nat. Mater, 17 (2018) 610-617. https://doi.org/10.1038/s41563-018-0105-6

55. A.J. Davenport, C. Padovani, B.J. Connolly, N.P.C. Stevens, T.A.W. Beale, A. Grosob, Marco Stampanonic, Synchrotron X-Ray Microtomography Study of the Role of Y in Corrosion of Magnesium Alloy WE43, Electrochem. Solid-State Lett. 10 (2007) C5-C8. doi: 10.1149/1.2400727

56. T. Cain, L.G. Bland, N. Birbilis, J.R. Scully, A compilation of corrosion potentials for magnesium alloys, CORROSION 70 (2014) 1043-1051. https://doi.org/10.5006/1257

57. K. Gusieva, C.H.J. Davies, J.R. Scully, N. Birbilis, Corrosion of magnesium alloys: the role of alloying, Int. Mater. Rev. 60 (2015) 169-194. https://doi.org/10.1179/1743280414Y.0000000046

58. A.D. Sudholz, K. Gusieva, X.B. Chen, B.C. Muddle, M.A. Gibson, N. Birbilis, Electrochemical behaviour and corrosion of Mg-Y alloys, Corros. Sci. 53 (2011) 2277-2282.

https://doi.org/10.1016/j.corsci.2011.03.010

59. D.S. Gandel, M.A. Easton, M.A. Gibson, T. Abbott, N. Birbilis, The influence of zirconium additions on the corrosion of magnesium, Corros. Sci. 81 (2014) 27-35.

https://doi.org/10.1016/j.corsci.2013.11.051 